\title{
Phylogeny of the Genus Dichotrachelus (Coleoptera: Curculionidae: Cyclominae)
}

\author{
Massimo Meregalli ${ }^{1, *}$, Christoph Germann ${ }^{2}$ (1), Marco V. Bernasconi ${ }^{3}$ and Piero Cervella ${ }^{1}$ \\ 1 Department of Life Sciences and Systems Biology, University of Turin, Via Accademia Albertina 13, \\ 10123 Torino, Italy; piero.cervella@unito.it \\ 2 Naturmuseum Solothurn, Klosterplatz 2, 4500 Solothurn, Switzerland; germann.christoph@gmail.com \\ 3 Natur-Museum Luzern, Kasernenplatz 6, 6003 Luzern, Switzerland; Marco.Bernasconi@lu.ch \\ * Correspondence: massimo.meregalli@unito.it; Tel.: +39-011-6704553
}

Received: 7 May 2018; Accepted: 5 July 2018; Published: 18 July 2018

\begin{abstract}
A phylogenetic analysis of the genus Dichotrachelus (Curculionidae: Cyclominae) was carried out, based on a morphological matrix and, for some species, on mitochondrial cytochrome oxidase I sequences. Bayesian Inference, Maximum Likelihood and Maximum Parsimony were implemented and the results were compared. The genus is found to be isolated in the subfamily, not related to the only other Palaearctic tribe (Hipporhinini) and possibly nearer to the south-American genera of Cyclominae of the tribe Listroderini. Among these, Macrostyphlus is also equally associated to mosses as the host plant. In Dichotrachelus, two main clades were recognized, one distributed in the western part of the Mediterranean region (Iberian Peninsula, northern Africa and southern France) and the second distributed in the Alps and Apennines. Within each clade, some differentiated monophyletic subgroups could be identified. An evaluation of the most important characters that led to the phylogenetic reconstruction indicated the male genital sclerite as the most useful structure to characterize the different clades.
\end{abstract}

Keywords: Dichotrachelini; systematics; morphology; evolution; mt-Cox1

\section{Introduction}

The genus Dichotrachelus Stierlin, 1853 includes 59 species from southern Europe and North Africa [1]. The genus belongs to the subfamily Cyclominae, tribe Dichotrachelini Hoffmann, 1957. Within the subfamily, its relationships are largely unknown [2] and no sister group to Dichotrachelini has been recognized. All species of Dichotrachelus are wingless, with a very low mobility, and are either associated with the forest environment, or-more often-with the alpine zone above the timberline. Each species usually has a restricted (or very restricted) range, and, in some cases, only one or very few populations are known. The genus has raised much interest since its description, and after a sequence of new species being named, a first revision was proposed in 1878 [3]. Since then, other than descriptions of new species, taxonomic revisions of local faunas have been provided for Switzerland [4], for the Iberian Peninsula [5-7], for France [8,9], and for Italy [10-12]. A complete revision of the genus was proposed in 1971 [13]. In the latter paper, the author recognized some species-groups and suggested a biogeographical scenario. Some remarks on relationships among the Iberian and north-African species and their historical biogeography were provided in 1987 [7], based on a discussion of the most important morphological characters, but without a cladistic analysis. More recently, several remarks on the Swiss species were given [14-16], and a checklist for Switzerland was provided $[17,18]$. A first attempt to reconstruct the phylogeny and phylogeography of the genus, limited to the Saxifraga-associated alpine species, was given based on a Bayesian analysis of morphological characters and mitochondrial cytochrome oxidase I ( $m t$-Cox1 hereafter) sequences [19], 
updated in 2015 [20]. Some additional species of the genus were also included in a more generic Barcode-approach on Swiss Alpine weevils [21].

Herein, we propose a phylogenetic analysis for the entire genus Dichotrachelus, based on a morphological database matrix, as well as on $m t$-Cox 1 sequences available for some species, in order to support the main clades (or species groups) and recognize the synapomorphies that define these groups. Available sequences of other Cyclominae were used in a first attempt at recognizing the affinities of Dichotrachelus within Cyclominae.

\section{Material and Methods}

\subsection{Samples Origin}

See Table I in the supplementary materials for a list of the species and specimens used, and for authorship and year of publication of the names. Specimens for molecular analyses were sampled by the authors. The weevils were hand-collected, immediately killed in $95 \%$ ethanol and preserved at $-20{ }^{\circ} \mathrm{C}$. Attempts to recover complete sequences of other species from dry collection specimens were seldom successful, and usually did not provide any reliable data. For the morphological analysis, samples from Meregalli's collection were used. Almost all species were included in the morphological matrix, except for D. elongatus and D. ulbrichi, species only known from the types, or, for the former, from very few specimens which could not be analysed, and the descriptions of which are insufficiently detailed to permit the scoring of the character states used for the study. Different subspecies of the same species were united with the nominal species, with the exception of D. knechti. This species was classified as a subspecies of D. stierlini in [1], but in the morphological analysis some of the character-states were distinct from those of $D$. stierlini, hence we have included it in the study. Sequences of the other species of Cyclominae were retrieved from GenBank.

\subsection{Outgroup Selection}

The selection of an outgroup proved particularly complex, since, as previously reported, there are no suggested sister groups of the tribe Dichotrachelini. The only other taxa of the subfamily Cyclominae present in the Palaearctic region belong to the tribe Hipporhinini, but only $m t$-Cox1 sequences of Gronops lunatus are available for this tribe. However, Hipporhinini do not seem to share any close relationships based on either external or genital morphology. One of the authors (CG) discovered Cyclominae associated with mosses in high elevation habitats of Ecuador. These belong to the genus Macrostyphlus Kirsch, 1889 (Listroderini LeConte, 1876, a tribe distributed in the Americas, Australia, New Zealand and Tristan da Cunha [22]). These Macrostyphlus specimens have some morphological resemblance to Dichotrachelus, and $m t$-Cox1 sequences showed that Dichotrachelus shares more sites in common with Macrostyphlus than with Gronops: D. rudeni, for example, has 667/775 sites in common with Macrostyphlus and 625/775 in common with Gronops, and the translated sequences have 226/258 sites of amino acids in common with Macrostyphlus and 207/258 in common with Gronops. A similar situation also occurred for the other species of the genus. Furthermore, when other taxa of Cyclominae, for which sequences are available, were tested, Dichotrachelus showed more differences from Gronops than from any of the other species of Cyclominae. Macrostyphlus was used as the nearest outgroup for the analyses, since it was also possible to use it for the morphological matrix; Gronops lunatus was used as a more distant outgroup. Otiorhynchus pseudonothus (Entiminae) was used as the outgroup for the Cyclominae analysis.

\subsection{Morphological Data}

Coding was conducted in a quantitative way and all characters were treated as non-additive. Scores were assigned based on the analysis of the various species, without any a-priori evaluation. Therefore, the state in the outgroups was not necessarily scored as 0. Morphological characters were selected in part according to the literature $[7,19]$, with some more characters added for this 
study. Their selection had to consider the extreme morphological uniformity among species of the genus, particularly those associated with mosses. Many of the characters generally used in the morphological analyses showed either a limited amount of variation, or variation that seems to appear by parallelism in various species, or even occurs among different specimens of the same species. These traits, which seemed to be independent of the phylogenetic affinities, were therefore excluded from the analysis. Genitalia were cleared in hot $10 \% \mathrm{KOH}$ and carefully dissected. Aedeagi were observed dry, female terminalia and the sclerite of the internal sac of the penis were placed in histology resin (Mounting Medium Leica CV Ultra) after dehydration in ethanol 95\% and passage through xylene. Photographs were taken with a Nikon Coolpix P6000 mounted on a Leica S6E stereomicroscope. A series of photographs at different focal planes were taken and stacking was performed with Zerene Stacker 1.04 (Zerene Systems LCC). We identified 59 discrete characters, 38 based on external morphology and 21 based on genitalia, with special attention given to the sclerite of the internal sac of the penis (Table II, Supplementary Material). The biology (mosses or Saxifraga) was added since host-plant associations in weevils are considered to reflect phylogenetic lineages [23].

\subsection{Molecular Data}

Total DNA was extracted non-destructively from the entire specimen by placing the whole animal body in $400 \mu \mathrm{L}$ of $5 \mathrm{M}$ guanidine-isothiocyanate, after separating the combined head + pronotum from the rest of the body to maximize DNA extraction [24]. Extraction and PCR were performed for a proportion of the species in the molecular laboratory of the Department of Life Sciences of the University of Turin, Italy, and for the remaining species in the molecular laboratory of the University of Geneva, Switzerland, within the frame of SwissBOL (Swiss Barcoding of Life: www.swissbol.ch). In both laboratories an $829 \mathrm{bp}$ fragment of $m t$-Cox1 was amplified with the following primers: forward C1-J-2183 (Jerry), 5'-CAACATTTATTTTGATTTTTTGG-3' and reverse L2-N-3014 (Pat), $5^{\prime}$-TCCAATGCACTAATCTGCCATATTA-3' [25]. In Turin, reactions were performed in a volume of $20 \mu \mathrm{L}$ with HotStarTaq Master Mix (Qiagen, Hilden, Germany); the PCR program comprised an initial denaturation at $95^{\circ} \mathrm{C}$ for $15 \mathrm{~min}$, followed by 10 cycles of $30 \mathrm{~s}$ at $94{ }^{\circ} \mathrm{C}, 45 \mathrm{~s}$ at $60 \geq 50{ }^{\circ} \mathrm{C}$ (lowering the annealing temperature each cycle $1^{\circ} \mathrm{C}$ ), 2 min at $72{ }^{\circ} \mathrm{C}$ followed by 30 cycles of $30 \mathrm{~s}$ at $94{ }^{\circ} \mathrm{C}$, $45 \mathrm{~s}$ at $50{ }^{\circ} \mathrm{C}, 2 \mathrm{~min}$ at $72{ }^{\circ} \mathrm{C}$, and a final extension cycle of $15 \mathrm{~min}$ at $72{ }^{\circ} \mathrm{C}$. The reaction products were visualized by agarose gel electrophoresis, with successive purification from the gel. Sequencing was performed by an external service (Genechron, Roma, Italy). In Geneva, reactions were performed in a $20 \mu \mathrm{L}$ total volume with $0.60 \mathrm{U}$ Taq (Roche, Basel, Switzerland), $2 \mu \mathrm{L}$ of $10 \mathrm{X}$ buffer containing $20 \mathrm{mM} \mathrm{MgCl} 2,0.8 \mu \mathrm{L}$ of each primer $(10 \mathrm{mM}), 0.4 \mu \mathrm{L}$ of a mix containing $10 \mathrm{mM}$ of each dNTP (Roche) and $0.8 \mu \mathrm{L}$ template DNA of an unknown concentration. The PCR program comprised an initial denaturation at $95{ }^{\circ} \mathrm{C}$ for $5 \mathrm{~min}$, followed by 35 cycles of $95{ }^{\circ} \mathrm{C}$ for $40 \mathrm{~s}$, annealing at $42{ }^{\circ} \mathrm{C}$ for $45 \mathrm{~s}$ and $72{ }^{\circ} \mathrm{C}$ for $1 \mathrm{~min}$, with a final elongation step at $72{ }^{\circ} \mathrm{C}$ for $8 \mathrm{~min}$. PCR products were then directly sequenced bi-directionally on an ABI 3031 automated sequencer (Applied Biosystems, Foster City, CA, USA).

Forward and reverse chromatograms were examined with Chromas (https://technelysium. com.au/wp/chromas). Multiple sequence alignment was performed with Mega6 (http://www. megasoftware.net) using default parameters and manually correcting ambiguities. After alignment, sequences were trimmed at the ends, reducing the length to a segment of $775 \mathrm{bp}$. All sequences were deposited in GenBank.

\subsection{Phylogenetic Analysis: Morphology}

Bayesian inference (BI) was performed using MrBayes 3.2 [26]. We ran two runs with four MCMC chains, each for two million generations under a binary MarkovK $+\Gamma$ model, sampling every 500 generations. The first $25 \%$ generations were discarded (burn-in) and convergence was evaluated with the average standard deviation of split frequencies. Goodness of mixing was assessed by looking at the acceptance rate of swaps between adjacent chains [27]. 
Parsimony analysis (MP) was performed with TNT 1.1 [28] with the New Technology Search option, selecting all four search methods (Sectorial Search, Drift, Ratchet and Tree Fusing), using default parameters, and independently finding the optimal score 100 times. Trees were TBR-collapsed and the consensus tree was calculated with Majority Rule. Tree statistics were calculated using a TNT script (stats.run) included with the package. Character-states and synapomorphies common to all trees were mapped onto the resulting consensus tree.

Maximum likelihood (ML) was performed with raxmlGUI1.1 [29] using a MarkovK $+\Gamma$ model. Support values were computed with 1000 bootstrap replications.

\subsection{Phylogenetic Analyses: $m t$-Cox1}

We obtained 84 sequences from 27 species. Sequences of other species, used as outgroups, were retrieved from GenBank (see supplementary material, Table I). Some of the Dichotrachelus sequences were identical and were only computed once in the alignments. All the sequences are $775 \mathrm{bp}$ except that of $D$. rossettoi, which has a gap in position 137-178. It could not be determined whether this gap is true or due to artefacts that may have occurred during the sequencing procedure. The overall quality of the sequence of $D$. rossettoi was, however, relatively low.

Pairwise distance was calculated with MEGA6, implementing the p-distance model.

BI was performed using MrBayes 3.2 [26]. The nuclear substitution model was set to the "codon" evolutionary model [30] implemented in MrBayes, also according to [31]. To recognize the codons, the aligned sequences were translated to the respective amino acids with Mega6 and checked for congruity among the species. This was accomplished by deleting the first nucleotide in the sequence, thus obtaining $774 \mathrm{bp}$ long sequences. We ran two runs with four chains, each for two million generations, sampling every 500 generations, using reversible jump Monte Carlo Markov Chain (MCMC) [32]. The heterogeneity of substitution rates among different sites was modelled with a four categories discretized $\Gamma$ distribution and with a proportion of invariable sites. The first $25 \%$ of generations were discarded (burn-in) and convergence was evaluated with the average standard deviation of split frequencies. Goodness of mixing was assessed by looking at the acceptance rate of swaps between adjacent chains [27].

\section{Morphological matrix}

See Figures 1-3 for some of the morphological characters used. See also illustrations in $[7,19]$, in particular for other detailed drawings and photographs of the male genital sclerite ([7], Figures 245-301; [19], Figures 28-53).

1. Size. $0=$ small, length less than $5 \mathrm{~mm} ; 1=$ large, length more than $5 \mathrm{~mm}$.

2. Rostrum, dorsal margins. $0=$ subparallel; $1=$ distinctly convergent anteriad; $2=$ broadened at midlength; $3=$ broadened at base.

3. Rostrum, width at antennal insertion. $0=$ almost half as wide as at base; $1=$ almost as wide as at base.

4. rostrum, vestiture on median part. $0=$ almost completely covered with scales; $1=$ almost completely lacking scales.

5. Rostrum, vestiture of scales on median part. $0=$ scales adherent to integument; $1=$ scales distinctly raised.

6. Rostrum length $0=$ short, about $1.5 \times$ as long as wide; $1=$ slender, almost twice as long as wide; $2=$ very slender, more than twice as long as wide

7. Apex of rostrum. $0=$ roughly punctured; $1=$ striate; $2=$ smooth, punctures or striae absent.

8. Vestiture of body, shape of scales: $0=$ round or elliptical; $1=$ narrow, long hair-like.

9. Vestiture of body, shape of setae. $0=$ long hair-like; $1=$ elliptical; $2=$ spatulate, broadened apicad; 3 = very shortly oval, almost rounded; 4 = polygonal.

10. Shape of setae above eyes. $0=$ as long as or slightly longer than setae on rostrum; $1=$ much longer than setae on rostrum; 2 = setae almost indistinct, not raised; 3 setae absent.

11. Scrobe, dorsal view. 0 = expanded outside of rostrum; 1 = not expanded outside of rostrum. 


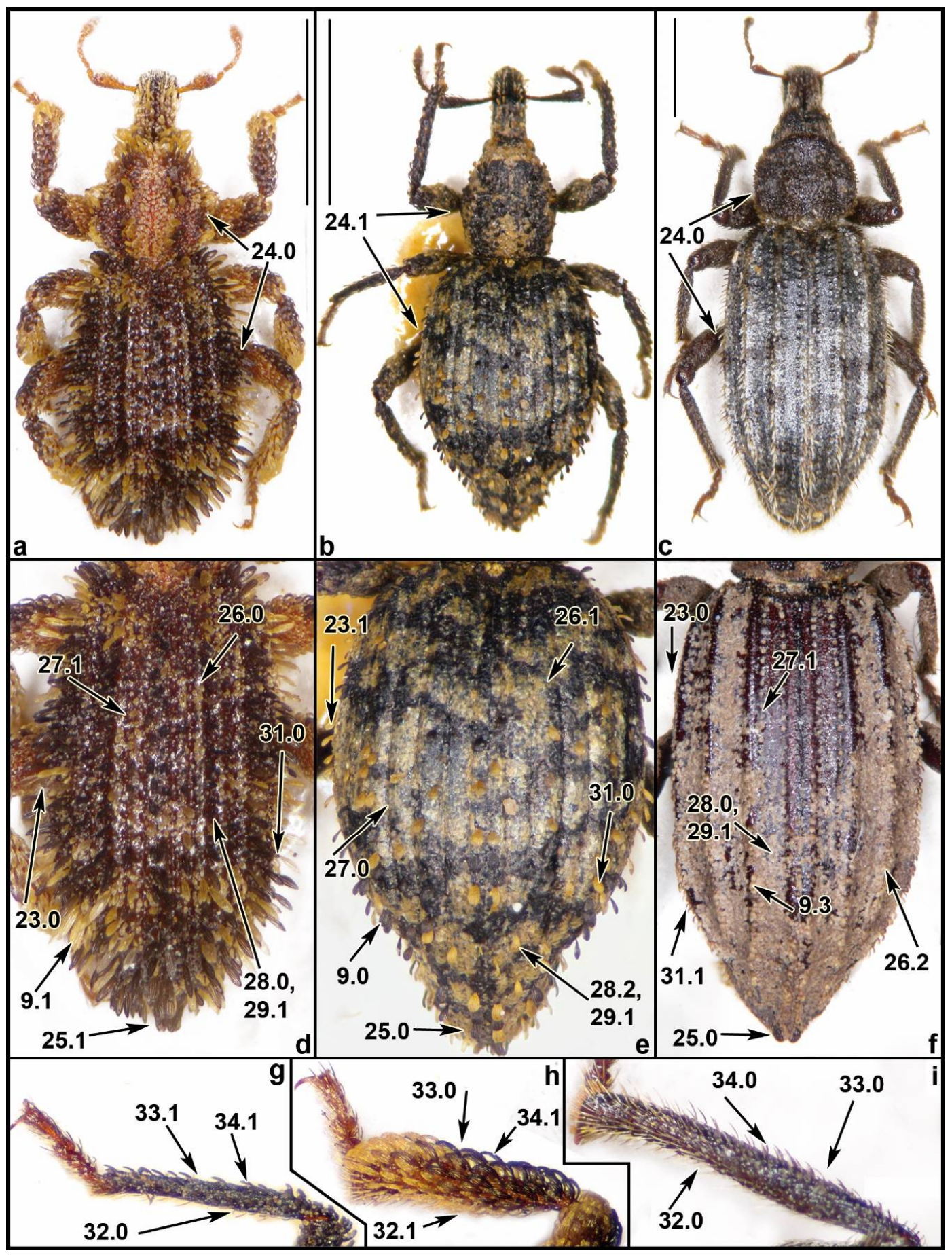

Figure 1. Body of Dichotrachelus baldensis Barajon (a); D. afer Peyerimhoff (b); D. manueli Marseul (c). Elytra of D. baldensis (d); D. afer (e); D. linderi (Fairmaire) (f). Protibia of D. afer (g); D. baldensis (h); D. manueli (i). Not in scale. Bars for body size. $2 \mathrm{~mm}$. 


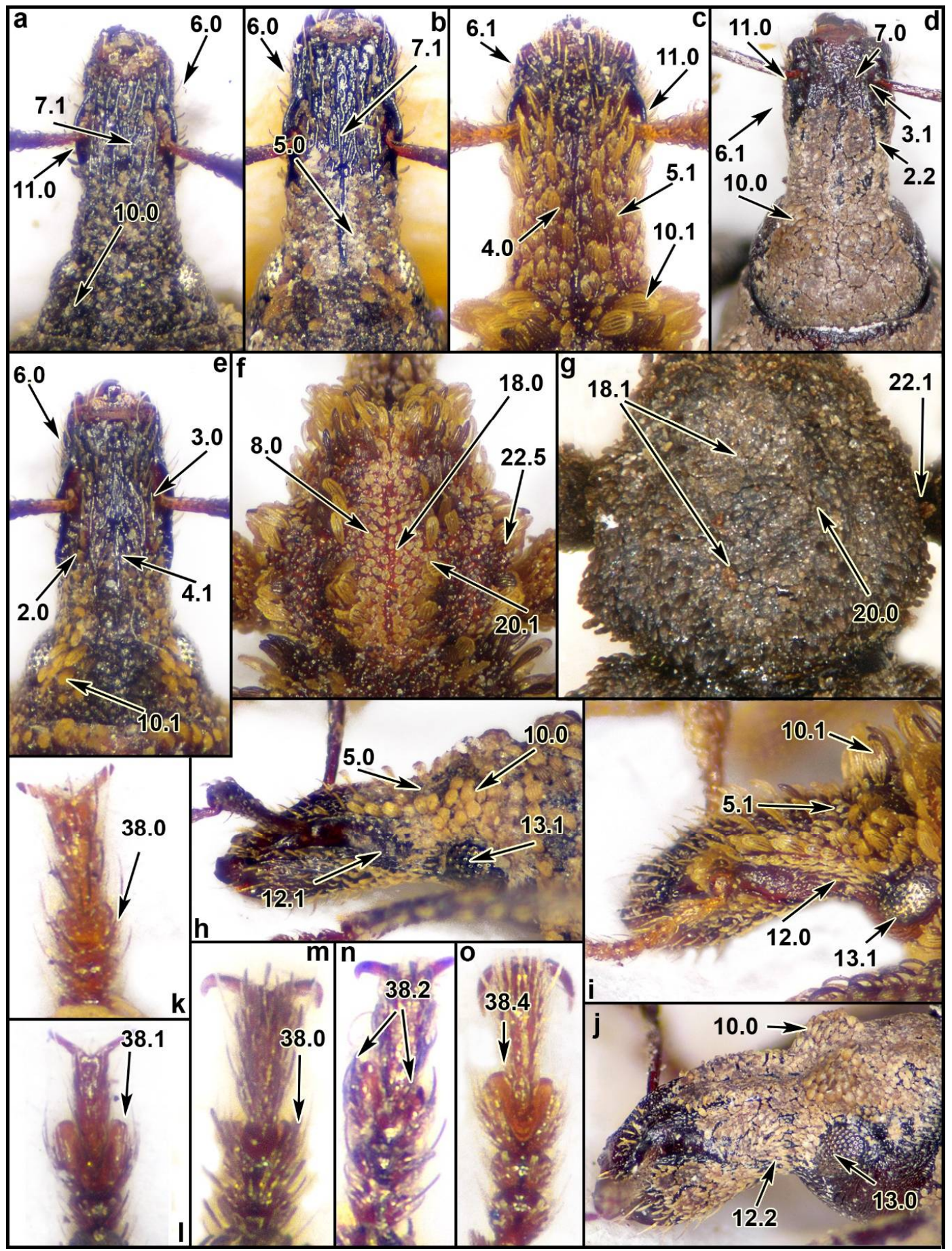

Figure 2. Rostrum, dorsal side, of Dichotrachelus augusti F. Solari (a); D. laurae Meregalli (b); D. baldensis Barajon (c); D. linderi (Fairmaire) (d); D.pericarti Osella (e). Rostrum, lateral side of D. rifensis Meregalli (h); D. baldensis (i); D. linderi (j). Pronotum of D. baldensis (f); D. sulcipennis Stierlin (g). Protarsus of D. baldensis (k); D. meregallii Osella (1); D. augusti F. Solari (m); D, negrei Gonzalez (n); D. rifensis (o). Not in scale. 


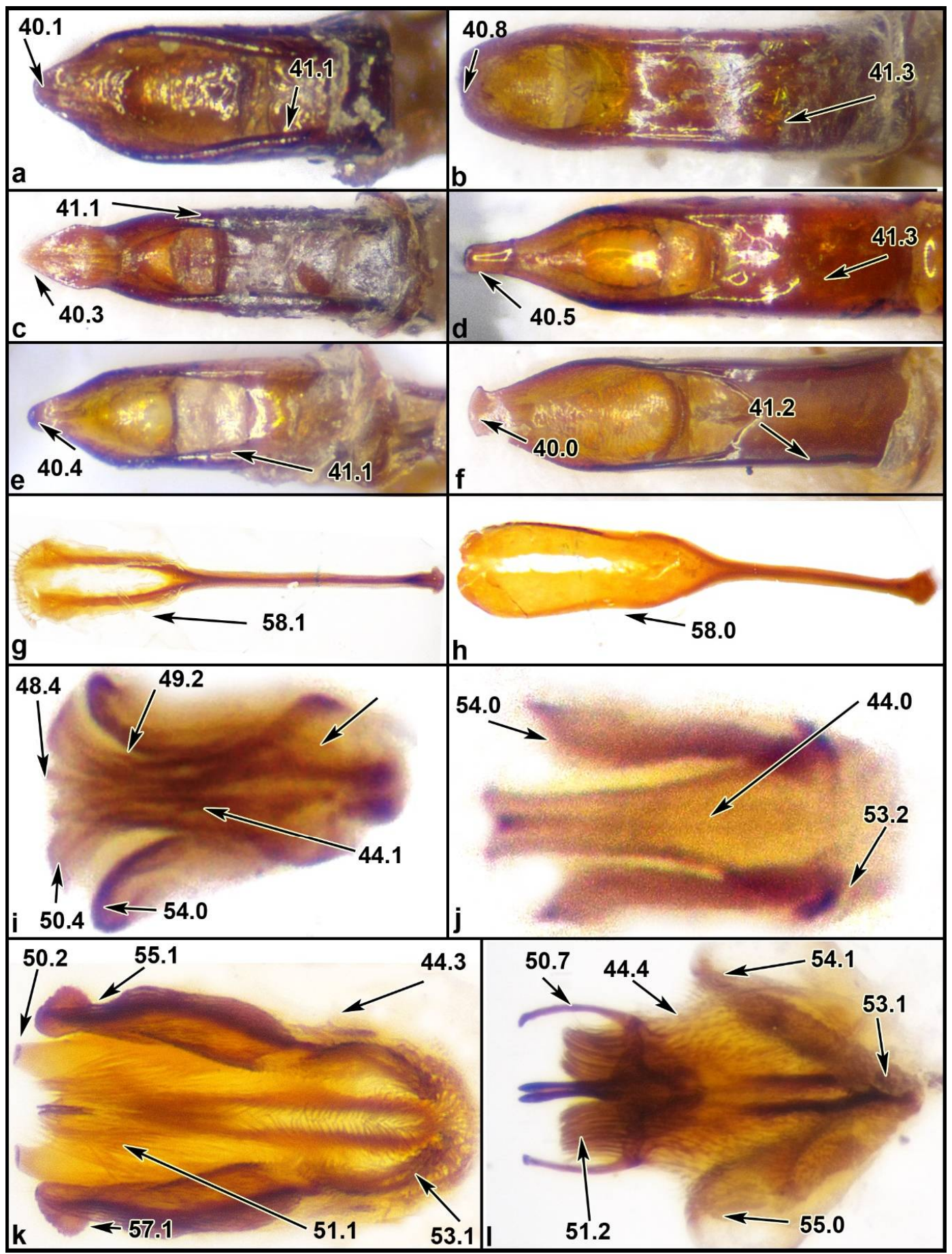

Figure 3. Penis of Dichotrachelus baldensis Barajon (a); D. cantabricus Franz, 1954 (b); D. meregallii Osella (c); D. devillei Osella (d); D. negrei Gonzanez (e); D. augusti F. Solari (f). Sternum VIII of female of D. sterlini Gredler (g); D. sulcipennis Stierlin (h). Male genital sclerite of D. baldensis (i); D. graellsii Perris (j); D. baudii (Seidlitz) (1); D. sulcipennis (k).

12. Shape of setae at base of scrobe, in front of eyes. $0=$ elliptical; $1=$ hair-like; $2=$ oval; $3=$ absent. 13. Eyes, number of ommatidia. $0 \geq 50 ; 1 \leq 30 ; 2=$ about 40 .

14. Shape of setae on antennal scape. $0=$ slender; $1=$ spatulate; 2 = hair-like.

15. Shape of antennomere 1 of funicle. $0=$ longer than wide; $1=$ globose.

16. Shape of antennomere 2 of funicle: $0=$ very slender; $1=$ moderately longer than wide. 
17. Pronotum, ratio length $/$ width. $0=$ transverse; $1=$ subquadrate; $2=$ longer than wide.

18. Pronotum, shape of median groove. $0=$ not distinctly separated in anterior and posterior groove; 1 = distinctly divided into two grooves separated by a median relief.

19. Pronotum, deepness of median groove. $0=$ deep; $1=$ weakly impressed; 2 = groove flat, margins not raised.

20. If $19 \neq 2$, shape of median groove. $0=$ very broad; $1=$ broad; $2=$ narrow.

21. Pronotum, shape of dorso-lateral grooves. $0=$ weakly impressed longitudinally; $1=$ isolate, round and deeply impressed; 2 = undifferentiated.

22. Pronotum, shape of lateral margins of pronotum in dorsal view. $0=$ narrowed anteriad and basad and parallel in median part; $1=$ converging anteriad almost from base; $2=$ regularly and slightly broadened medially; 3 = distinctly incised medially; 4 = linearly broadened to apical third; $5=$ distinctly broadened at midlength .

23. Elytra, sides. 0 = subparallel for most of length; 1 = regularly broadened laterally.

24. Elytra, shape. $0=$ not much broader than pronotum at maximum width; $1=$ almost twice as broad as pronotum, particularly in female.

25. Elytra, apex. $0=$ prominent in female; $1=$ regularly rounded also in female.

26. Elytra, intervals convexity. $0=$ odd intervals convex on dorsal part; $1=$ all intervals flat; $2=$ odd intervals convex from base to apex.

27. Elytra, shape of punctures on striae. $0=$ punctures fuse, striae linear and deep, narrow; $1=$ punctures distinct, spaced, as broad as intervals.

28. Elytra, distribution of setae. $0=$ present also on even intervals; $1=$ absent from even intervals; $2=$ absent on dorsum of even intervals and present on their declivity.

29. if $28 \neq 1$, shape of elytral setae on even intervals. $0=$ distinctly shorter than setae on odd intervals; 1 = almost identical to setae on odd intervals.

30. Setae on declivity part of suture. $0=$ not distinctly more dense than setae on dorsum; $1=$ setae much more dense than on dorsum.

31. Setae on odd intervals of elytra. $0=$ dense; 1 = spaced.

32. Tibiae. $0=$ slender, more than $5 \times$ as long as wide; $1=$ robust, at most $4 \times$ as long as wide.

33. Vestiture of setae on tibiae. $0=$ dense; $1=$ sparse.

34. Shape of setae on tibiae. $0=$ very slender, almost hair-like; $1=$ thicker, spatulate.

35. Apex of foretibiae. $0=$ almost straight; $1=$ distinctly curved inwards.

36. Ventrites, vestiture. $0=$ scales dense; $1=$ scales sparse.

37. Shape of scales on ventrites. $0=$ slender; $1=$ oval.

38. Shape of segment 3 of tarsus. $0=$ as wide as 2 , lobes not broadened; $1=$ broader than segment 2 , as long as wide, both lobes equally broadened; $2=$ broader than segment 2 , only internal lobe broadened; 3 , broader than segment 2 in male, not broadened in female; 4 = weakly lobed, only slightly broader than segment 2 , slightly asymmetrical.

39. Penis, shape. $0=$ very long and narrow, tube more than $5 \times$ as long as wide; $1=$ regular, not very slender, tube less than $5 \times$ as long as wide.

40. If $39=1$ penis, apical lamella. $0=$ subtruncated, angularly broadened at sides; $1=$ regularly shortly narrowed, subacute, not curved upwards; 2 = scarcely narrowed, apex round; $3=$ with a flat, triangularly acute apex; $4=$ as 1 , curved upwards; $5=$ elongated lamella, rounded at apex, upwards directed; $6=$ very slender, regularly narrowed; $7=$ long regularly narrowed, subacute, upwards directed; $8=$ short, curved downwards, acute; $9=$ scarcely narrowed, long upwards directed.

41. If $39=1$ penis, sclerotization of dorsum: $0=$ sides sclerotized to centre, basal part of ostium sharply delimited, margins of sclerotization sharply delimited; $1=$ sides sclerotized to half of width; 2 = sides sclerotized only marginally, basal part of ostium not clearly delimited; $3=$ dorsum strongly sclerotized; $4=$ dorsum membranous.

42. If $39=1$, shape in lateral view. $0=$ scarcely curved; $1=$ curved. 
43. Length of internal sac: $0=$ long, genital sclerite placed in correspondence of apex of temones; $1=$ moderately long, sclerite placed in correspondence of midlength of temones; $2=$ short, sclerite placed at base of temones; 3 = sclerite absent.

44. If $43 \neq 3$, shape of shield of sclerite. $0=$ broadened basad and strongly narrow apicad, with downward curved apical plate; $1=$ broadened basad, moderately narrowed at midlength, slightly broadened apicad; 2 = subquadrate, very broad basad and apicad; $3=$ rectangular, almost not restricted medially; $4=$ short, broadened at midlength; $5=$ oblong, bifurcate apicad, not curved; $6=$ linearly converging from very broad base to apex; $7=$ same as 6 , triangularly curved downwards at apex.

45. If $44=0$, shape of lateral arms at apex of tectum. $0=$ almost undifferentiated; $1=$ developed, shorter than median plate; 2 = very short and thick; 3 = thick and highly developed, as long as median plate.

46. If $44=0$, presence of setae on underside of apex of shield. $0=$ present; $1=$ absent.

47. If $44=0$, apex of downward curved apex of shield. $0=$ bifurcate; $1=$ narrowed apicad; 2 = sides broadened, apex broadly rounded; $3=$ sides parallel, apex barely rounded.

48. If $44=1$, horn at apex of tectum. $0=$ absent; $1=$ longer than arms, slightly bifurcate at apex; 2 = obtuse, barely developed; 3 = as long as arms, broadened apicad; 4 = very minute, shorter than arms

49. If $44=1$, width of shield at first third of length. $0=$ half as wide as at base; $1=$ scarcely narrower than at base; 2 = uniformly narrowed.

50. if $44 \neq 0$, anterior arms of genital sclerite. Anterior arms of genital sclerite: $0=$ absent; $1=$ very minute at side of apical plate; 2 = short, thick, with nearly the same thickness from base to apex, sharply curved downwards, only base of arm visible from above; $3=$ short (much shorter than apical horn), thick at base and narrowed apicad, not or barely curved downwards, entire arm visible from above; 4 = moderately elongated, thick, distinctly and evenly curved downwards, the proximal half of its length visible from above; $5=$ very long, narrow, sharply curved in its proximal part, reaching underside of sclerite; $6=$ very long and narrow, prominent forwards beyond margin of tectum, not tapered apicad; $7=$ same as 6 but distinctly tapered apicad.

51. if $44 \neq 0$, presence of setae on underside of tectum near apex. $0=$ absent; $1=$ scarce; $2=$ dense and prominent beyond anterior margin of sclerite.

52. Ratio between length and width of tectum of genital sclerite. $0=$ very long, ratio length $/$ width $>4$; $1=$ long, ratio length $/$ width $3-4 ; 2=$ ratio $1 / \mathrm{w} 2-3 ; 3=$ ratio $1 / \mathrm{w} 1.5-2 ; 4=$ subquadrate, ratio $1 / \mathrm{w} 1.1-1.3$.

53. Position of base of valves of genital sclerite. $0=$ at basal third of sclerite; $1=$ at base of sclerite; $2=$ valves joined basad behind base of sclerite; $3=$ valves reaching base but not joined

54. Distal extension of valves of genital sclerite. $0=$ almost reaching apex of tectum; $1=$ distant from apex of tectum

55. Lower margin of valves of genital sclerite. $0=$ entire; $1=$ bilobate.

56. Thickness of anterior part of valves. $0=$ not thickened; $1=$ distinctly thicker than the basal part

57. Structure of distal part of valves of genital sclerite. $0=$ without an apical lobe or a subapical process; $1=$ with an apical lobe; $2=$ with a subapical process.

58. Female sternite VIII, side of plate. $0=$ sublinearly convergent from near base to apodeme (plate shape subtriangular); 1 = subparallel for most of length (plate shape subrectangular); 2 = curved with maximum width at basal third (plate shape oval); $3=$ as 2 , but plate much longer (plate shape elliptical); 4 = slightly curved inwards near apodeme.

59. Food plant. $0=$ moss; $1=$ Saxifraga; $2=$ other Phanerogams.

\section{Results}

The results and discussion are primarily based on the data obtained from the Bayesian Inference. Topology and supports of the BI consensus tree were checked for congruence with topologies obtained with ML and MP. Usually, the terminal clades were uniformly present in all analyses, with various 
supports, whereas deep phylogeny, i.e., relationships among the large monophyletic groups, was not always clearly defined and in part differed among the analyses.

\subsection{Morphological Analysis}

Dichotrachelus always resulted in a monophyletic unit (BI: 92\% posterior probability (pp); ML: 74\% bootstrap (bs); MP: 70\% symmetric resampling (sr), Bremer support 3; Figure 4). In ML and MP Macrostyphlus and Dichotrachelus clustered in the same clade, whereas in BI the two genera resulted in a polytomy (Figures 5 and 6).

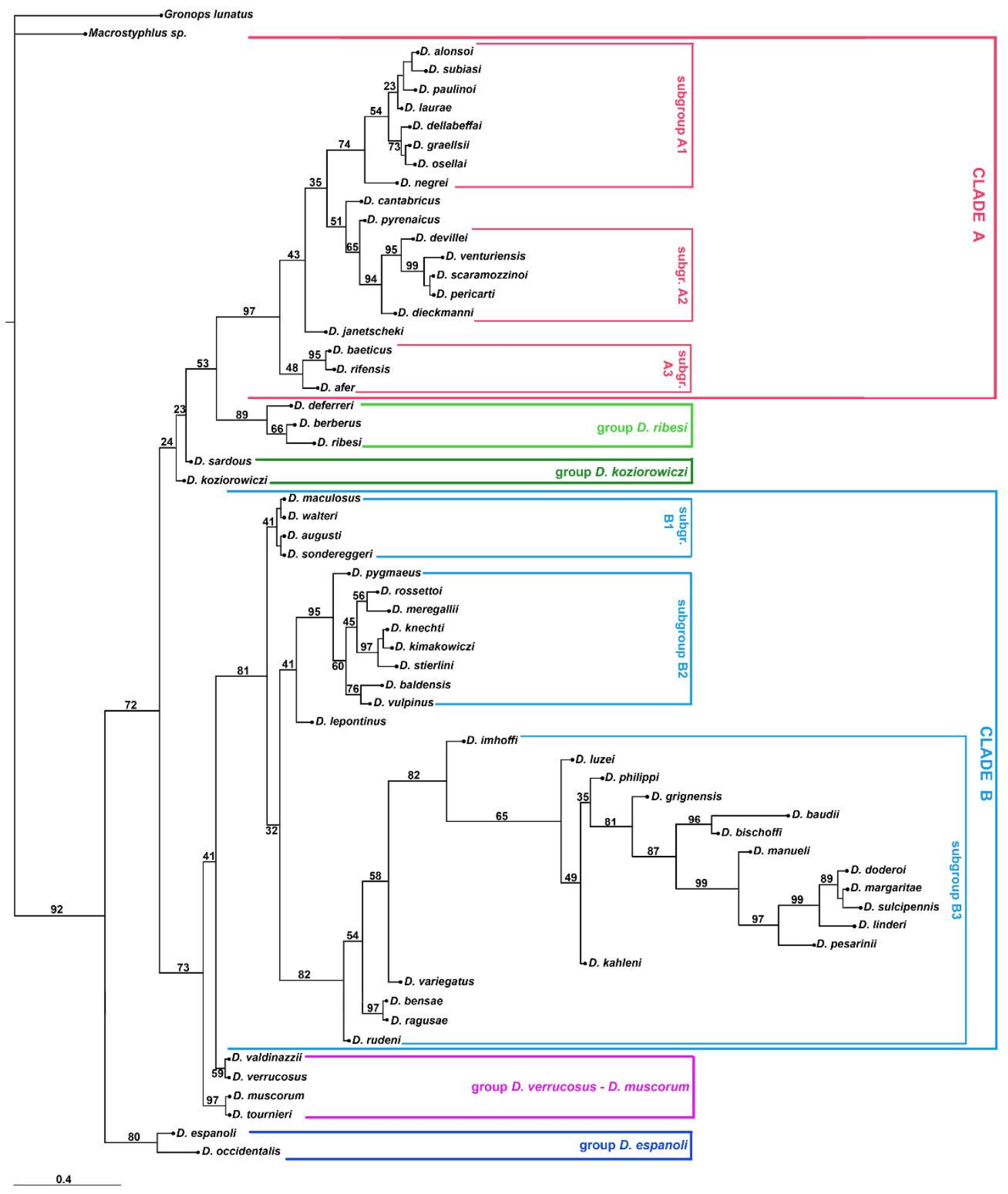

Figure 4. Morphological analysis. Bayesian Inference consensus tree. Numbers above branches indicate posterior probability. Scale bar unit: expected changes of state per character. See discussion for remarks on the clades and species group. 


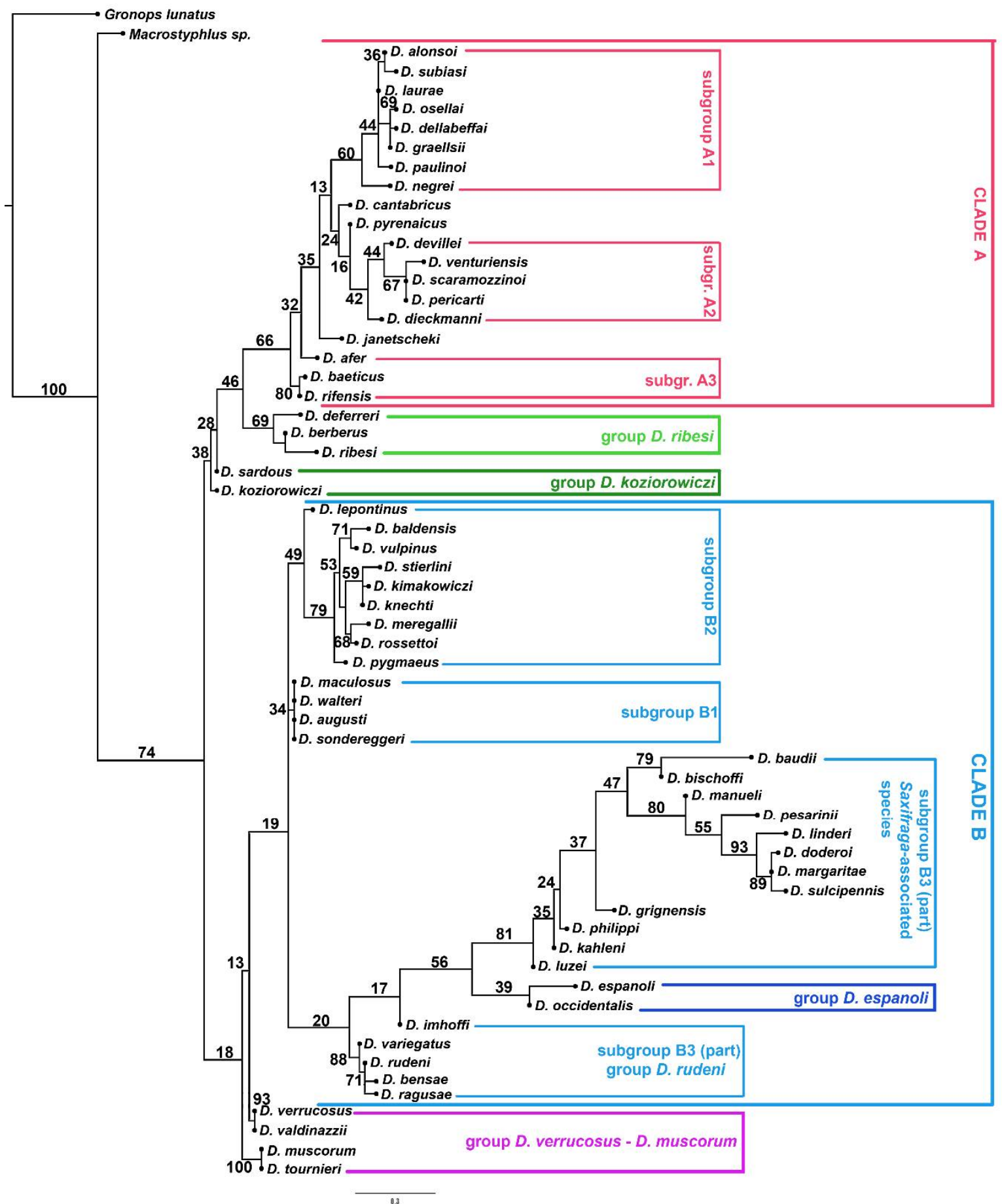

Figure 5. Morphological analysis. Maximum Likelihood consensus tree. Numbers above branches indicate bootstrap value. Scale bar unit: expected changes of state per character. Clades and species group are indicated as shown by the Bayesian analysis. 


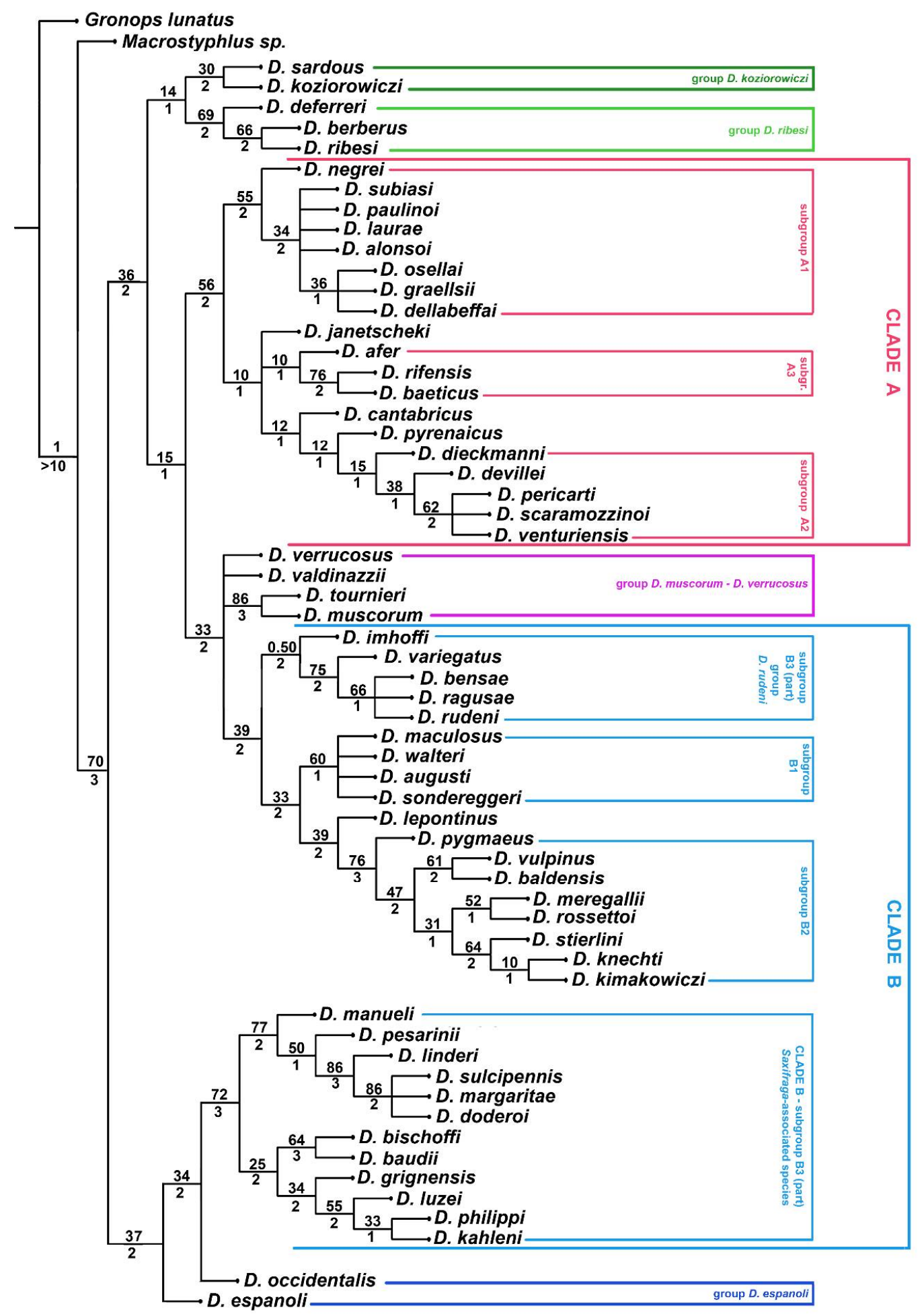

Figure 6. Morphological analysis. Maximum Parsimony consensus tree. Numbers above branches indicate symmetric resampling; numbers below branches indicate Bremer support. Length 281, consistency index $=0.45$, retention index $=0.82$. Clades and species group are indicated as shown by the Bayesian analysis.

Within Dichotrachelus, some relatively well-supported groups were differentiated. A first group (Clade A, BI: 97\% pp; ML: 66\% bs; MP: 56\% sr, Bremer 2) includes the majority of the species present in the Iberian peninsula and the massifs of central-southern France and northern Africa. Within this 
clade, some subgroups correspond to reciprocally closely related species, which are distributed in the same region. Subgroup A1 (BI: 74\% pp; ML: $60 \%$ bs; MP: 55\% sr, Bremer 2) encompasses species that are present in central and northern Spain, excluding the Pyrenean region, and Portugal: D. graellsii, $D$. dellabeffai and $D$. osellai, that form a monophyletic species complex, present in all analyses, and with $73 \%$ support in BI, plus D. alonsoi, D. laurae, D. paulinoi and D. subiasi, the reciprocal placement of which was not univocally defined. D. negrei was the sister to the previous species. Another subgroup in Clade A delimited species from north-eastern Spain and the massifs of central-southern France: D. dieckmanni, D. devillei, D. scaramozzinoi, D. pericarti and D. venturiensis (Subgroup A2, 94\% pp in BI). Among these species, the Spanish D. dieckmanni clustered as the sister taxon to the other species, and the last three taxa always formed a well-supported monophyletic complex. Two species from the Pyrenees and the Cantabrians (D. pyrenaicus and D. cantabricus) were weakly associated with Subgroup A2. Clade A also includes some Dichotrachelus from southern Spain and northern Africa: D. afer from the Algerian Djurdjura and the two vicariant species living on the two sides of the Gibraltar strait, D. baeticus from Mount Mulhacen in Sierra Nevada, southern Spain and D. rifensis from Mount Tidiquin, in the Rif chain, northern Morocco (Subgroup A3). A further species from southern Spain, Sierra Nevada, D. janetscheki, clustered in an "intermediate" position between Subgroups A3 and Subgroups A1 and A2 (as sister to A1-A2). Three very peculiar species from, respectively, north-western Spain (D. ribesi), southern Spain (D. deferreri) and the Djbel Tazzeka in northern Morocco (D. berberus), the reciprocal relationships of which appeared to be quite strong (BI: 89\% pp; ML: 69\% bs; MP: 69\% sr, Bremer 2), were together weakly supported as the sister group to Clade A under BI and ML analyses (BI: 53\%; ML: $46 \%$ bs). Under MP, however, these three species clustered in a different clade, together with $D$. sardous and D. koziorowiczi from Sardinia and Corsica, respectively. These two latter species clustered as sister to Clade A in both BI and ML, but this placement lacked any support.

A second major clade (Clade B, $81 \%$ pp in BI) included all the species from the Alps and Apennines. Inside this unit, three large subgroups were differentiated. One subgroup (Subgroup B1), not statistically supported in BI and ML (respectively, $41 \% \mathrm{pp}$ and $34 \%$ bs in ML), and weakly supported in MP (60\% sr, Bremer 1), is exclusive to the western Alps, and includes four very similar species: D. maculosus, D. walteri, D. augusti and D. sondereggeri. A second subgroup (Subgroup B2, BI: $95 \%$ pp; ML: 79\% bs; MP: 76\% sr, Bremer 3) includes many of the "small sized" species present in the entire Alpine chain and expanded to the Carpathians: D. meregallii, D. rossettoi, D. pygmaeus, D. kimakowiczi, D. stierlini, D. knechti, D. baldensis and D. vulpinus. A further species, D. lepontinus, from the mountains north-west of Lake Maggiore, in central-western Alps, clustered as sister to the taxa of Subgroup B2, in all the analyses, even though this placement was scarcely supported (BI: 41\% pp, ML: 49\% bs; MP: 39\% sr, Bremer 2). The last group in Clade B (Subgroup B3) encompasses the remaining moss-associated Alpine species, and those from the Apennines: D. rudeni, D. bensae, $D$. variegatus, D. ragusae and D. imhoffi. These last species clustered in BI as sister to the species associated with Saxifraga, already discussed in $[19,20]$, with a high support in BI $(82 \%)$. The same topology also resulted in the ML analysis, except for the placement within Subgroup B3 of D. espanoli and D. occidentalis (see below for further comments). In MP, however, the D. imhoffi-D. rudeni complex clustered as sister to the other small-sized, moss-associated Alpine species of Subgroups B1 and B2, whereas the Saxifraga-associated species formed a separate clade, as sister to the clade of the small-sized, moss-associated species.

Two Pyrenean taxa, D. muscorum and D. verrucosus, and its vicariant D. valdinazzii (originally described, probably correctly, as a subspecies of $D$. verrucosus), plus the enigmatic $D$. tournieri from the surroundings of Geneva (Switzerland), clustered in two groups, as sister to the Alpine-Apennine taxa in all analyses.

Two more Dichotrachelus from the Pyrenees, D. espanoli and D. occidentalis, clustered as sister to the remaining Dichotrachelus in BI, but were instead correlated with the Saxifraga-associated species in MP and ML, as sister to the alpine species, even though without statistical support. 


\subsection{Molecular Analyses}

The $m t$-Cox 1 analysis was relatively congruent with the results of the morphological analysis, with some exceptions. Since only a few species were available, our results cannot be conclusive at present. A first Clade (Clade A) corresponds to Clade A in the morphological analysis, with a minor difference in the suggested relationships of $D$. venturiensis, which was here associated with the Spanish species rather than with $D$. devillei.

More differences between the morphological and the $m t$-Cox1 analyses are apparent for some of the alpine and apennine species (Clade B), with particular regard to the subgroup B2 as circumscribed by the morphological analysis. In the molecular analysis the D. imhoffi-D. rudeni complex was not directly related to the Saxifraga-associated taxa, but rather it clustered as a sister clade to the group of D. kimakowiczi, D. kraussi and D. vulpinus. A further species that was part of Subgroup B2, D. knechti, in the molecular analysis was placed as sister to the Saxifraga-associated species, even though the support was quite low ( $56 \% \mathrm{pp})$. D. meregallii and D. rossettoi clustered in separate lineages, whereas D. lepontinus, a species placed as sister to Subgroup B2 in the morphological analysis, was here associated with Subgroup B1, i.e., the D. maculosus complex, even though with low support (51\% pp). The complex of species feeding on Saxifraga also clustered in a strongly supported clade (93\% pp) in the $m t$-Cox 1 analysis. The relationships among these last species were almost identical in the morphological and the molecular analyses.

In the Cyclominae BI analysis Dichotrachelus formed a fully supported clade, distinct from the other Cyclominae (Figures 7 and 8). Weak possible relationships with Listroderini, in particular the genera Puranius Macrostyphlus and Listronotus, were suggested, but without statistical support.

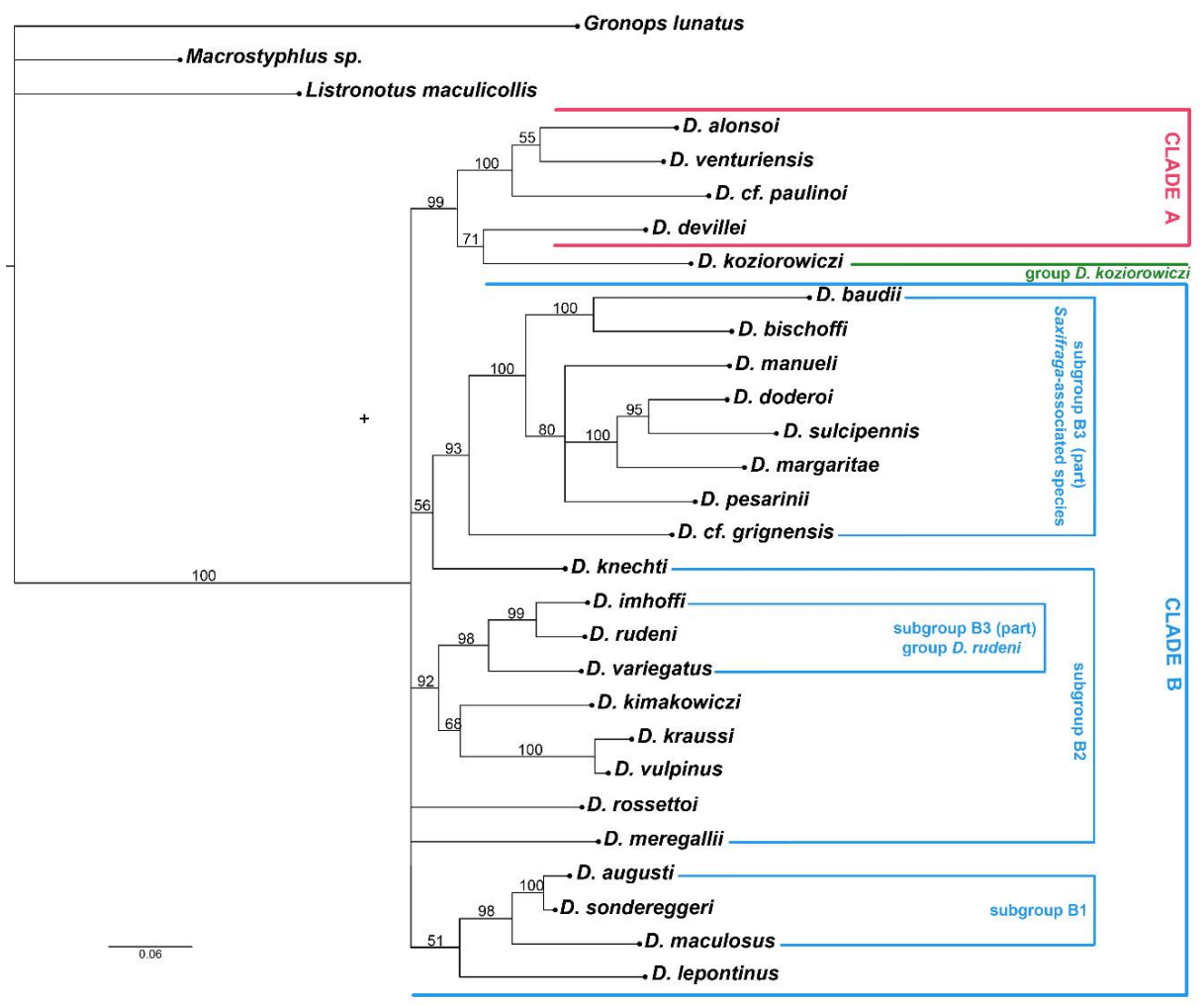

Figure 7. Mitochondrial cytochrome oxidase I analysis, Dichotrachelus. Bayesian Inference consensus tree (50\% majority rule). Numbers above branches indicate posterior probability. Scale bar unit: expected substitutions per site. Clades and species group are indicated as shown by the Bayesian analysis based on morphology. 


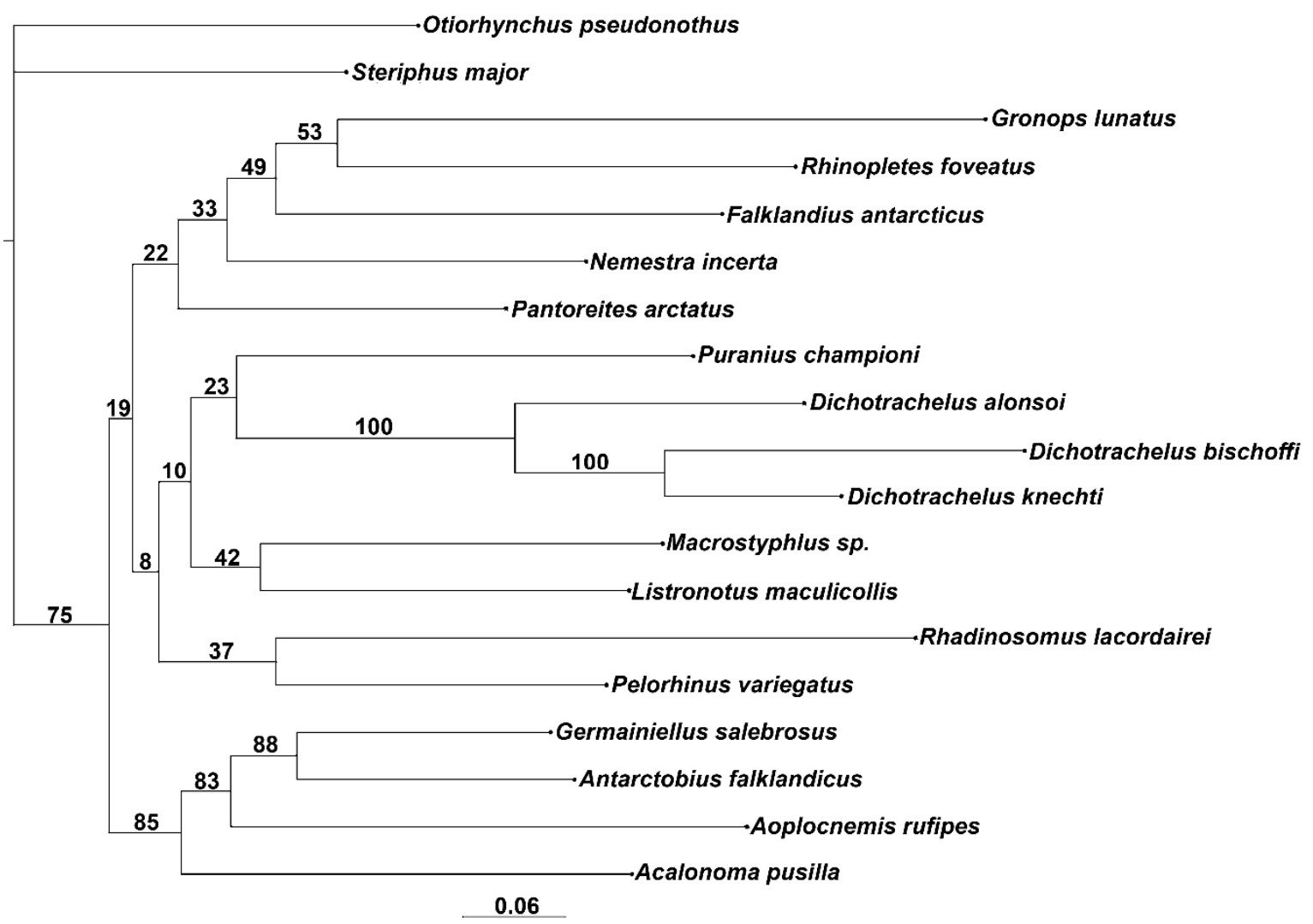

Figure 8. Mitochondrial cytochrome oxidase I analysis, Cyclominae. Bayesian Inference consensus tree. Numbers above branches indicate posterior probability. Scale bar unit: expected substitutions per site.

\subsection{Pairwise Distance}

In the aligned sequences of the Dichotrachelus, 458 out of 775 sites (59\%) were conserved. When translated to amino acids, 195 out of 258 (75.6\%) sites were conserved. Hence, a large part of the variable sites regarded the third position of the codon, in cases when the third nucleotide of the codon does not result in a different amino acid.

Dichotrachelus vs. Macrostyphlus, Listronotus and Gronops. Median pairwise distance in base sequences of Dichotrachelus vs. Macrostyphlus sp. was 0.1667, with a mean distance of 0.1659 (Tables III and IV). The lowest distance was found in D. rudeni, with a value of about 0.14 , and the highest was in the Saxifraga-associated species, with a value of $0.17-0.19$. The median pairwise distance vs. Gronops lunatus was 0.1925 , the mean distance was 0.1937 , and it was quite constant in all species. The median distance of Dichotrachelus vs. Listronotus maculicollis was 0.1743 , and the mean distance was 0.1780 . When the sequences were translated to amino acids, the distance of Dichotrachelus vs. Macrostyphlus sp. was quite low (median pairwise distance 0.1026, mean distance 0.1076), and only slightly lower than the distance vs. Listronotus maculicollis (respectively 0.1106 and 0.1108 ), whereas the distance vs. Gronops was about twice as great (median distance 0.2000, mean 0.1980).

Interspecific distance. The distance between different species in the base sequence varied from about 8 to $18 \%$, depending on the reciprocal affinities, with the lower values being found among species belonging to the same clade. Distance between closely related sister species was between $7-8 \%$ and $12 \%$ : D. alonsoi and D. paulinoi differed by $11.5-12 \%$ in base sequences, and $4 \%$ in amino acids; D. margaritae differed by $11 \%$ from $D$. sulcipennis and $7-8 \%$ from $D$. doderoi, corresponding to, respectively, $5.7 \%$ and $3.6-4 \%$ in amino acids.

Intraspecific distance. Specimens of different populations of the same species, or more specimens of the same population, were available for some taxa. Variation was usually quite limited, and often 
it did not result in different amino acids, or at most, in the replacement of three to four amino acids. In D. maculosus variation was between 0 and $2.8 \%$, and this variation was related to the different populations: specimens from Switzerland differed up to $2.8 \%$ from those from the southern and western part of the range, in south-western Piedmont and in south-eastern France. This variation resulted in a maximal substitution of $0.16 \%$ of the transcribed amino acids (four amino acids out of 258). All D. rudeni specimens examined came from southern Switzerland and bordering areas of northern Italy; interpopulation variation among them in base sequences was between 0.5 and $1.7 \%$, with a variation in the amino acid sequence of 0 to $1.2 \%$. In D. koziorowiczi, however, the two specimens that were sequenced, found in two different localities in Corsica, one at high altitude and one in a forest habitat, differed by $6.2 \%$ in base sequences and $1.2 \%$ in amino acids.

Intrapopulation distance. It was possible to obtain some data on intrapopulation variation in D. bischoffi: six of the eight specimens from Col de Bardoney, in the Aosta Valley, that were sequenced did not show any variation, and the other two differed by only a single site, not resulting in a different amino acid. In $D$. knechti no variation was detected among the five specimens, again all from $C o l$ de Bardoney. The two specimens sequenced of $D$. pesarinii differed by seven sites, but again this did not result in different amino acids.

No synapomorphy in amino acids or base sites was seen for any clade, even though some variation apparently characteristic of a single species, or of closely related species, could be detected when many specimens of the same taxon were available. For example, all specimens of D. maculosus examined (16) have a Glycine replacing an Alanine in position 83 and a Serine replacing a Methionine or a Leucine in position 244 . The related $D$. doderoi and $D$. margaritae, apparently vicariant species distributed in the western Alps, south of the Susa Valley, share a Threonine replacing an Alanine in position 88 and a Threonine replacing an Isoleucine in position 229 in the eight specimens examined; these can be considered as synapomorphies for the two sister species.

\section{Discussion}

The discussion is mainly based on the results of the morphological analyses, since $m t$-Cox 1 was only available for a part of the species, which, moreover, were not uniformly representative of all the distinct clades that resulted from the morphological analysis. The topology taken into account was the one obtained by the BI analysis, since it is considered to outperform parsimony [33]. Nevertheless, cases of incongruence among the results of the other methods of analysis implemented are considered and further discussed.

\subsection{Relationships of Dichotrachelus within Cyclominae}

Cyclominae, in phylogenetic analyses based on a variety of datasets, has been shown to be a paraphyletic taxon [34]. The classification within the subfamily was recently revised [2], and considered to include eight tribes, mostly restricted to the southern hemisphere. However, the composition of the tribes is also uncertain, and some appear to be paraphyletic, or even polyphyletic [2,34]. Palaearctic species are only found in the Cyclominae tribe Hipporhinini, which is mainly composed of African and Australian taxa, and Dichotrachelini, comprising the Palaearctic genus Dichotrachelus [1,2] and, doubtfully, the African genus Adichotrachelus Hoffmann, 1965 [35] (Figure 8). To date, phylogenetic relationships of Dichotrachelus within the Cyclominae are unclear [2]. We are aware that the use of the single $m t$-Cox 1 marker does not allow the inference of deep phylogenies with confidence, because of its high variability and subsequent saturation effect for taxa separated for a long time [36,37], particularly regarding the third nucleotide of the codon, which has the highest substitution rate [38]. However, $m t$-Cox1 gave good information on relationships in Curculionidae Cryptorhynchinae [39] and in surveys on Curculionoidea [40], and particularly on the "Broad-nosed weevils" (Entiminae and Cyclominae), the mitogenome helped in reconstructing phylogenies [34]. Hence, we will now shortly discuss some indications that can be drawn from our analyses about possible relationships of the genus within the subfamily. We emphasise that these data are intrinsically 
incomplete and therefore must only be considered as simple hypotheses to be tested when a more complete set of molecular markers and Cyclominae taxa is available.

The most interesting remark regards the rather evident absence of any close relationship between Dichotrachelus and the other Palaearctic Cyclominae, members of the tribe Hipporhinini, neither regarding their external and genital morphology, nor based on the $m t-C o x 1$ sequences. Indeed, among the few species of Cyclominae for which sequences were available, Gronops had the highest $p$-distance from Dichotrachelus, a distance similar to that of non-Cyclominae taxa (around 0.20, that is, saturation of $m t-C o x 1$ ). Furthermore, in the Cyclominae BI analysis it did not show any relationship with Dichotrachelus.

If the absence of close relationships between Dichotrachelus and the Palaearctic Hipporhinini seems to be well supported, the present data do not clarify with equal reliability the true affinities of the genus. In the $m t$-Cox 1 analysis Macrostyphlus (Cyclominae: Listroderini, a predominantly south-American tribe, the range of which also includes Australia, New Zealand and Tristan da Cunha Islands [41]) showed a $p$-distance of about 0.16 , but also other species of Listroderini and Aterpini had a p-distance varying between 0.16 and 0.18 . In BI the genus clustered as a separate, fully supported lineage, part of a (poorly supported) clade also including Macrostyphlus and Puranius. Additionally, in the recent combined Cyclominae-Entiminae analysis [34], where a more complete set of markers was used, Dichotrachelus was weakly associated with Puranius ([34], Figure 1), and thus with the Listroderini subtribe Macrostyphlina, as defined in [42]. As previously said, we used Macrostyphlus as one of the outgroups in our study because we had specimens available for the morphological matrix. Macrostyphlus sp. also shares mosses as the host-plants of both larvae and adults (Germann, pers. obs. on two species of Macrostyphlus from Ecuador). Cryptogam herbivory is rare in Curculionoidea [43,44], and it has been considered to be often a secondary, recent strategy response to the harsh habitat conditions that occurred during the Pleistocene glaciations [45]. This explanation cannot be advocated for Dichotrachelus, the only Palaearctic weevil taxon associated with cryptogams, or for Macrostyphlus. Both taxa appear to be primarily associated with mosses, since the ecosystems of the regions that they colonize were not influenced by, or were largely protected from, quaternary glaciations. However, even if the unusual biology shared between Dichotrachelus and Macrostyphlus is taken into account, there is so far no conclusive evidence that it derives from a common ancestor. Regarding Adichotrachelus, from Kenya, Mount Aberdare, a species never collected again after its description, it has not yet been possible to examine it, since the type specimen is not present in the Paris Natural History Museum (Perrin, pers. comm.). Its similarity was regarded as being due to convergence [12,13], but relationships between these genera may be possible. The presence of a taxon related to Dichotrachelus in the mountains of Kenya could in fact indicate a possible route of dispersal of its ancestors northwards from a primary centre of differentiation in tropical or subtropical Africa, even though the exclusive presence of taxa of Dichotrachelus in territories derived from the fragmentation of the western Peri-Tethys plates, and their apparent absence from any of the territories derived from the African plate (Atlas of Morocco, for example), does not seem to support this hypothesis. In any case, since the actual distribution of Cyclominae is strongly suggestive of a primary Gondwanian differentiation [2], relationships in the deep phylogeny of Dichotrachelini with taxa from the southern hemisphere are possible, and even likely. Ancestral dispersal towards the Iberian plate via the present day American plate, where many Listroderini live, may have occurred, since Cyclominae apparently differentiated during the mid-Cretaceous [46], more than 100 mya, thus before the split of the American continent from the Afro-European plates, an event dating to about 80 mya [47].

\subsection{Phylogenetic Lineages in Dichotrachelus}

Our results indicate that the genus is composed of two major lineages, Clade A and Clade B, as presented in Figure 4, with a few additional species, the placement of which is still uncertain. Relationships among the major clades are still poorly disclosed, and the placement of some taxa is not univocally defined in the various analyses. 
Clade A. This clade includes the majority of the Iberian species, plus those of the massifs of southern France. All these species share a specific shape of the genital sclerite (Char. 45.0, Figure 3j). Its shield has a broad basal part and the sides are then regularly narrowed, up to the midlength, where it is between half and $1 / 3$ as wide as at the base. From here to the apex, the sides are more or less parallel. The apex has a downwards curved broad plate, rounded or sub-acute apicad, and, laterally, this plate presents two arms, which can be long, reaching the apex of the plate, or shorter, to very short and narrow. The narrow elliptical scales in front of the eyes, which are sometimes not clearly visible, (Char. 12.0) and the scales appressed to the integument on the frons (Char. 5.0) are other synapomorphies for this clade. Within this clade, some species-groups are morphologically more or less well differentiated. Only for a few of them were molecular data available, that confirm the monophyly of the clade.

The Iberian species belonging to Clade A share the very narrow elytral striae, the punctures of which are not clearly distinct, rather they form relatively deep lines, with much broader intervals (Char. 27.0). Among these species, a lineage of closely related taxa lives in the massifs of central and northern Spain (D. subiasi, D. paulinoi, D. laurae, D. alonsoi, D. osellai, D. graellsii and D. dellabeffai, Subgroup A1). These species share two additional genital synapomorphies, with the dorsal sclerotization of the penis not being clearly delimited (Char. 43.3) and the absence of setae on the lower part of the genital sclerite (Char. 52.0). D. negrei, from north-western Spain and northern Portugal, appears to be related to these species. It mainly differs inbecause the third tarsal segment is slightly, but distinctly, broadened (Char. 38.2, Figure 2n), besides some characters on the rostrum, partly homoplastic (Char. 3.1, 4.1).

The species from southern France of the D. pericarti complex (D. devillei, D. pericarti, D. scaramozzinoi, D. venturiensis), together with D. dieckmanni, from north-eastern Spain, form another apparently monophyletic group (Subgroup A2). These species share the shape of the apical part of the penis (Char. 40.5), with the exception of D. dieckmanni, the penis of which, even though with a rather similar shape, has a broader apical lamella, which moreover shows two angular lateral prominences. The species of the $D$. pericarti complex also differ from those of Subgroup A1 by the presence of setae on the lower side of the genital sclerite (Char. 52.1), the elytra being broadly ovate in females (Char. 24.1) and the distribution of setae on the even intervals, usually absent from the dorsum and present on the declivity (Char. 28.2). The elytral striae in these species are distinctly punctured (Char. 27.1). Two species from the Pyrenees and Cantabrians, D. pyrenaicus and D. cantabricus, are also part of Clade A. They have narrow, linear striae, and the former typically has very slender elytra and thepenis with a downwards curved apex, an autapomorphy not appearing in other taxa of the genus. The correct placement of these two species within the clade is still uncertain.

Another well-defined complex in Clade A, Subgroup A3, includes three species from southern Spain and northern Africa: D. afer, D. rifensis and D. baeticus. The two last species are morphologically extremely similar, sharing almost all of the character-states and thus representing a pair of sister species. This complex is characterized in particular by the odd intervals that are almost flat at their base (Char. 26.1), a state seldom present in the genus, as well as the shape of the apex of the genital sclerite (Char. 48.1) and the broad elytra in females. This last trait, anyway, may be partly homoplastic.

A further species belonging to Clade A is D. janetscheki, occurring in Sierra Nevada, mainly on the northern slopes. Although its precise relationships with other species of the clade are still uncertain, it shares several characters with the taxa of Subgroup A1, such as the narrow striae (Char. 27.0), the third tarsal segment not being bilobate, and the scarcely broadened female elytra.

Three taxa of Dichotrachelus known from very isolated localities appear to form a sister group to all these species of clade A. These are D. ribesi, from Sierra de Obac, in north-eastern Spain, the very similar D. berberus, from Djbel Tazzeka, in northern Morocco and possibly D. deferreri, found at $50 \mathrm{~m}$ a.s.l. in southern Spain. The inclusion of the latter in this group was only based on the morphological characters of the female, the only specimen known, and its position is therefore uncertain, as no information on the shape of the male genital sclerite was available. 
Clade B. This clade includes all the species occurring in the Alps and the Apennines, plus apparently a few species from the Pyrenees. The sequences of $m t$-Cox 1 were available for several of these species. However, the results between morphology and $m t$-Cox1 are only partly congruent.

One monophyletic clade, Subgroup B1, was recovered by both the molecular and the morphological analyses. It includes the species from the western and southwestern Alps of the D. maculosus complex (D. maculosus, D. walteri, D. augusti and D. sondereggeri). This complex is characterized by the very small third segment of tarsi (Char. 38. 0), the shape of the apical lamella of the penis, flattened and with two lateral acute projections (Char. 42.0) and a slightly differentiated structure of the apex of the genital sclerite, with a slightly broadened apex of horns (Char. 49.3), a trait shared with $D$. lepontinus. The latter species, according to the $m t$-Cox 1 analysis, appears indeed to be sister to the $D$. maculosus complex, from which it mainly differs in the slightly bilobed segment 3 of the tarsi. In all the morphological analyses another complex of species (Subgroup B2) was found to be monophyletic, with strong support ( $95 \%$ pp in BI). This group includes many of the remaining small-sized alpine Dichotrachelus. These species share some traits regarding the density of the elytral setae (Char. 32.0) and, with the exception of D. meregallii, also the shape of the penis (Char. 42.1). Within this group, some complexes of species seem to be reciprocally more closely related, such as D. vulpinus-D. baldensis and the complex including D. stierlini, D. knechti and D. kimakowiczi. However, in the $m t$-Cox 1 consensus tree D. knechti was separated from D. kimakowiczi, and placed instead in the clade including the Saxifraga-associated taxa, near its root and as sister to these (even though with low support). This position appears doubtful, since $D$. knechti shares all its characters with the taxa of Subgroup B, including the shape of the male genital sclerite. Therefore, we do not consider the placement resulted by the molecular analysis to be correct.

The disjunct range of D. kimakowiczi from all the other species of the genus, and in particular from its sister taxa distributed in the Eastern Alps, is remarkable. Vicariance between Alps and Carpathians, with a gap corresponding to the Dinarides, is not uncommon in montane flightless species, and it presumably originated during the late Tertiary orogenetic events that affected this region.

Two small-sized species, D. rossettoi and D. meregallii, had an uncertain classification, quite different between the morphological and the $m t$-Cox 1 analyses. As indicated by the molecular analysis, these two species could be old relicts, distantly related to the other alpine taxa of the genus. The shape of the genital sclerite clearly confirms that they belong to Clade B, but an isolated position in the clade is also suggested by some of the other morphological traits.

Additionally, the D. imhoffi-D. rudeni complex had a different placement in the various analyses. In the molecular analysis it formed a sister clade to the clade including some of the species of the morphological group B2, whereas in BI this complex was placed towards the root of the clade of the Saxifraga-associated species. In MP it clustered as sister to the small-sized species of the Subgroups B1 and B2. The placement suggested by the Bayesian analysis is supported by some characters that are shared between the $D$. imhoffi complex and the apparently less derived species of the Saxifraga-associated group, with particular regard to a somewhat "intermediate" structure of the genital sclerite.

Regarding the Saxifraga-associated species, our molecular and morphological analyses are congruent and reflect the classification already discussed [19]. The only difference with respect to the reconstruction proposed in [19] is the placement of D. baudii as the sister species to D. bischoffi also in the molecular analysis. This position appears to be correct according to the majority of the characters of the two species, with particular emphasis on the shape of the genital sclerite and the biology. In the molecular analysis reported in [19] D. baudii had clustered as sister to the whole Saxifraga-associated group, near its root. This placement was not considered to be correct, since it would imply a parallelism in the development of some 20 characters, including the very complex structure of the genital sclerite, almost identical between $D$. baudii and D. bischoffi, and also a double shift from mosses to Saxifraga as the host plants. In [19] the Bayesian analysis was performed by implementing the usual nucleotide substitution model (model "4by4" in MrBayes), whereas in the present study the "codon" model, 
which considers the codon as the substitution unit, was implemented. This model, according to the results of this study, seems to be less sensitive to the bias due to long-branch attraction and therefore it appears to perform better than the "4by4" substitution model, at least in the case of the codifying gene $m t$-Cox 1 for these weevils. Always regarding the Saxifraga-associated species, it can be noticed that they are not characterized by any synapomorphy, with respect to the other Dichotrachelus, in the $m t$-Cox 1 sequence. There are variations, occasionally typical of one or a few species, but not shared among all species of this subgroup.

D. koziorowiczi and D. sardous from Corsica and Sardinia are isolated from the other taxa. They are characterized by a peculiar shape of the genital sclerite, which shares its general structure with the Pyrenean species of the D. verrucosus-D. muscorum complex, even though in the latter the sclerite is much smaller. In the morphological analysis both groups cluster near the root of the entire genus, but since no molecular data are thus far available for the $D$. verrucosus complex, we prefer not to indicate any definite position for the group. One interesting point is the high pairwise distance $(6 \%)$ that was observed between the two specimens of D. koziorowiczi, one collected at high altitude, above the timberline, and one found in a beech forest of low altitude. Furthermore, from a morphological perspective, small differences between these forms were previously observed by the first author. These data suggest that two different species may be recognized in the Dichotrachelus from Corsica, one typical of the alpine habitat and one associated with the forest habitat. More specimens from various other populations from the two habitats are required in order to achieve more detailed information.

The relationships of three species from the Pyrenees, D. espanoli, D. occidentalis and D. elongatus, are particularly uncertain. These clustered in a separate clade, sister to all the other Dichotrachelus in BI, but were at the base of the Saxifraga-associated clade in MP and ML. This placement is supported by some traits, such as the relatively larger size, the shape of the rostrum and the scrobes, yet the shape of their genital sclerite does not show any similarities with the Saxifraga-associated species. Also their biology is not yet certain. D. occidentalis and D. elongatus were indicated to be living on Saxifraga [48], but this information should be confirmed, since very often mosses are found together with Saxifraga. Already in the past it was suggested that some species, indeed associated with mosses, could live on Saxifraga or both Saxifraga and mosses depending on the habitat or locality. This was, for example, reported for D. rudeni, D. alpestris and D. verrucosus [49], or D. imhoffi [12,13]. So, for the time being, we prefer to maintain the D. espanoli-D. occidentalis-D. elongatus complex as incertae sedis in the genus Dichotrachelus.

The distribution of the various clades is shown in Figure 9.

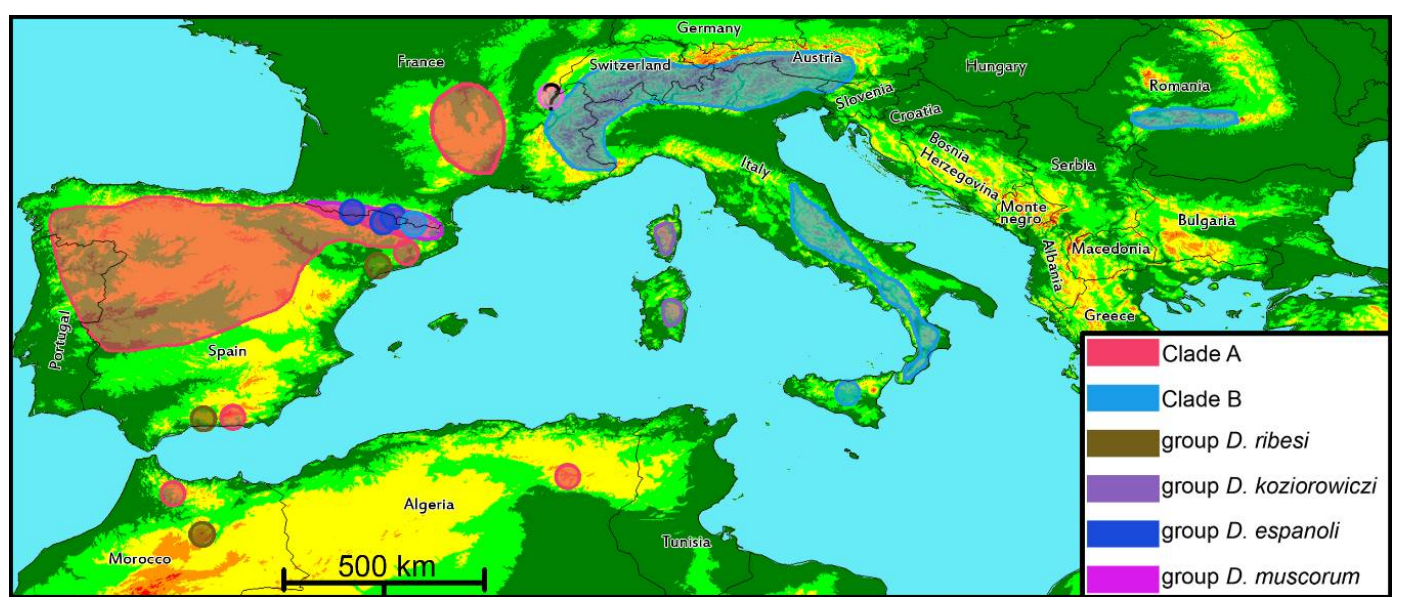

Figure 9. Distribution of the clades and species group of Dichotrachelus. Country level data downloaded from DIVA-GIS Free Spatial Data (http:/ / www.diva-gis.org/Data) and processed with DIVA-GIS. 


\subsection{Species-Groups}

Several species-groups in the genus were proposed $[12,13]$. Some of them are confirmed by our study, but in many cases the new information allows a more precise definition of the monophyletic groups, and placement of the species whose position is still not yet fully disclosed. Species-groups are informal categories and are not covered by the ICZN code, thus we do not necessarily follow the principle of priority for naming them.

a. Species-groups associated with mosses.

1. Species-group D. graellsii. It includes these reciprocally more closely related species:

a. D. graellsii, D. dellabeffai and D. osellai.

b. D. alonsoi, D. subiasi, D. paulinoi and D. laurae.

c. D. negrei.

Distribution. Northern and central Spain, Portugal.

2. Species-group D. pericarti. It includes these reciprocally more closely related species:
a. D. pericarti, D. scaramozzinoi, D. venturiensis, D. devillei and possibly D. dieckmanni
b. D. pyrenaicus.
c. D. cantabricus.

Distribution. Southern France, Pyrenees, north-eastern Spain, Cantabrians.

3. Species-group D. afer. It includes D. afer, D. baeticus and D. rifensis.

Distribution. Northern Algeria, northern Morocco, southern Spain.

These three species-groups form a fully supported monophyletic clade.

The relationships of $D$. janetscheki, from southern Spain, apparently sister to all species of clade A, should be confirmed. For this reason, we prefer not to include it in any of the previous groups.

4. Species-group D. ribesi. It includes D. ribesi, D. berberus and possibly D. deferreri.

Distribution. North-eastern and southern Spain, northern Morocco.

5. Species-group D. koziorowiczi. It includes D. koziorowiczi and D. sardous.

Distribution. Corsica, Sardinia.

6. Species-group D. muscorum. It includes D. muscorum, D. tournieri, D. valdinazzii and D. verrucosus. According to the examination of the holotype, D. tournieri might be a mislabelled specimen of D. muscorum. However, more research is required at its type locality, the surroundings of Geneva, Switzerland, before the hypothetical synonymy can be confirmed.

Distribution. Pyrenees, surroundings of Geneva, Switzerland (doubtful).

7. Species-group D. maculosus. It includes D. maculosus, D. walteri, D. augusti and D. sondereggeri.

Distribution. Western Alps.

8. Species-group D. stierlini. As for other groups, it is possible to recognize species more closely reciprocally related:

a. D. stierlini, D. knechti and D. kimakowiczi.

b. D. baldensis, D. vulpinus and D. pygmaeus.

Distribution. Alps, Carpathians.

D. rossettoi and D. meregallii might also be part of this group, even though they are quite isolated, and the $m t$-Cox1 data are not congruent with those of the morphological analysis. D. ulbrichi, from the 
eastern Alps, is not included in the present study since it was not possible to examine its type. However, the only specimen known is apparently, morphologically, sister to D. meregallii.

Also D. lepontinus might be part of this species-group, in a somewhat "intermediate" position linking group 7 to group 8 (more precisely, as the sister to group 8 ).

9. Species-group D. rudeni-D. imhoffi. It includes D. imhoffi, D. rudeni, D. variegatus, D. bensae, and D. ragusae.

Distribution. North-western to central Alps, Apennines, Sicily.

b. Species groups associated with Saxifraga

10. Species-group D. luzei. It includes D. luzei, D. kahleni, D. philippi and D. grignensis. Some characters of the genital sclerite of the latter indicate that it is a more derived species, which already shows some of the states present in the species of group 11.

Distribution. Eastern to central Alps.

11. Species-group D. manueli. It includes D. manueli, D. bischoffi and D. baudii. The latter species is morphologically strongly differentiated, due to the ovate scales being modified into long, hair-like scales not covering integument, and the possibly consequent smoothness of sculpture, with flat elytral intervals and pronotal grooves not impressed. However, its genital sclerite is almost identical to that of D. bischoffi, as is the general structure of the rostrum.

Distribution. Western Alps.

12. Species-group D. sulcipennis. It includes
a. D. pesarinii.
b. D. linderi.
c. D. sulcipennis, D. margaritae and D. doderoi.

Distribution. Central and Western Alps, eastern Pyrenees.

c. Species group with uncertain biology

13. Species-group D. espanoli. It includes D. espanoli, D. elongatus and D. occidentalis. As previously indicated, this group has a particularly uncertain position within the Dichotrachelus classification. As suggested by some of the characters, it might be closely related to the Saxifraga-associated species, possibly as a less derived species, but the shape of the male genital sclerite contradicts this hypothesis. Moreover, confirmed data on their biology remain absent.

Distribution. Central and eastern Pyrenees.

\subsection{Inter vs. Intraspecific Distance}

Our results show that the species are well characterized, with no intra- and interspecific overlap, with the unique exception of $D$. sondereggeri, which does not show any difference from $D$. augusti. This fact suggests that speciation occurred by vicariance following geographical isolation in these stenotopic and flightless weevils. In species with a broad range, such as D. maculosus, which also has a broad altitudinal range, comprised between 700 and more than $2500 \mathrm{~m}$ a.s.l., the relatively higher difference between the populations, up to almost $3 \%$, confirms that gene flow in the distance is reduced, so that, in the absence of true geographical barriers, only slow clinal variation occurs. In more localized taxa, the population consistence of which is probably also small, differences-not only for $m t$-Cox 1 , but also in morphological characters-appear to fix at a faster rate.

\subsection{Analysis of the Morphological Characters}

As previously mentioned, and demonstrated by the relatively low consistency index in the parsimony analysis, a large number of character-states appear by parallelism in various lineages. 
Furthermore, some of the apparent reversals are probably morphologically similar states appearing independently in different lineages. Some of these traits are obviously useful for single species differentiation, but they cannot be used to infer clade-specific relationships. Examples of these traits are, for example, (i) shape and ratios of antennal segments, particularly segments 1 and 2; (ii) shape of the funicle; (iii) density of the scales on ventrites, and more. These traits were used in the first analyses, but were discarded for the subsequent analyses, since they often had more than 15-20 passes in the classification obtained with MP, and were not synapomorphic for single clades (that is, both consistency and retention indexes for these traits were very low). In some cases, a single, broader defined state was used to show variation previously scored into different states. For example, the elytral setae, other than being long elliptical or hair-like, can have a more or less continuous variation between short oblong, ovate to short ovate, and spatulate, independently from the relationships among the species, and sometimes even with some intraspecific variation. Hence, short ovate-spatulate to oblong setae were scored as the same state.

Examination of some of the characters in detail indicates those that bear a stronger phylogenetical signal. Synapomorphies and autapomorphies are traced in Figure 10.

Size (Char. 1) clearly differentiates the Saxifraga-associated species, which are always much larger than the others. D. occidentalis is also a large species (as the related D. elongatus), but, as already discussed, the relationships of these species within the genus are not yet understood.

Rostrum, dorsal margins. All species associated with mosses have rostral sides that are more or less convergent (Char. 2.0), so that the ratio length/width of the rostrum is distinctly higher in these species than in those associated with Saxifraga. Those that are associated with Saxifraga have almost parallel-sided rostrum, sometimes slightly broadened at midlength, and scrobes are not broadened laterally, possibly following adaptation to the different host plants, habitats colonized, and feeding habits.

Rostral vestiture (Chars 4-5). Almost all species have a dense vestiture on the dorsum of rostrum (Char. 4.0), and only those from southern France of the D. devillei group (excluding D. venturiensis) differ in almost lacking scales on the median part of the rostrum (Char 4.1). However, the way scales are inserted characterizes the groups: in the species of clade A scales are flat and adherent to integument (Char. 5.0); in the small-sized species of clade B scales are obliquely inserted, suberect (Char 5.1), and in the large Saxifraga-associated species they are adherent to the integument again.

Rostral sculpture. The apex of the rostrum is rough, with irregular longitudinal glossy lines in the small species (Char. 7.1), or, alternatively, it is smoother, with irregular punctures (Char. 7.0), as in the Saxifraga-associated species. The D. rudeni complex differs from the other small-sized species in having the rostrum roughly punctured towards the apex. This character could support its hypothetical placement in the same clade as the Saxifraga-associated species, near its root. Species in this group, however, feed on mosses and share many of their characters with the other small-sized species, with $D$. imhoffi being somewhat morphologically intermediate.

Scrobes. The outer margin of the scrobes is dorsally expanded externally in the small species (Char. 11.0), and delimited by the outer margin of the genae in the larger species (Char. 11.1). Other traits correlated with the scrobes, such as length and direction of the lower margin, width of the posterior part, divergence between the upper and lower margin, and others, show considerable variation, apparently not correlated with the phylogenetic affinities. Hence, these traits were excluded from the final analysis. Scales in front of the eyes, in the basal part of the scrobes, are elliptical in the species of clade A (Char. 12.1), generally oval in the species of clade B (Char. 12.0), or even hair-like in a few other species (Char. 12.2).

Ommatidia. The small-sized, moss-associated species have small eyes (Char. 13.1), composed of a limited number of ommatidia, usually less than 30 , and about 40 in D. ribesi and D. baeticus. Only the large-sized species, associated with Saxifraga, have larger eyes, with more than 50 ommatidia (Char. 13.0). Also this trait may be associated with the different biology and the more exposed life on the Saxifraga clumps. 


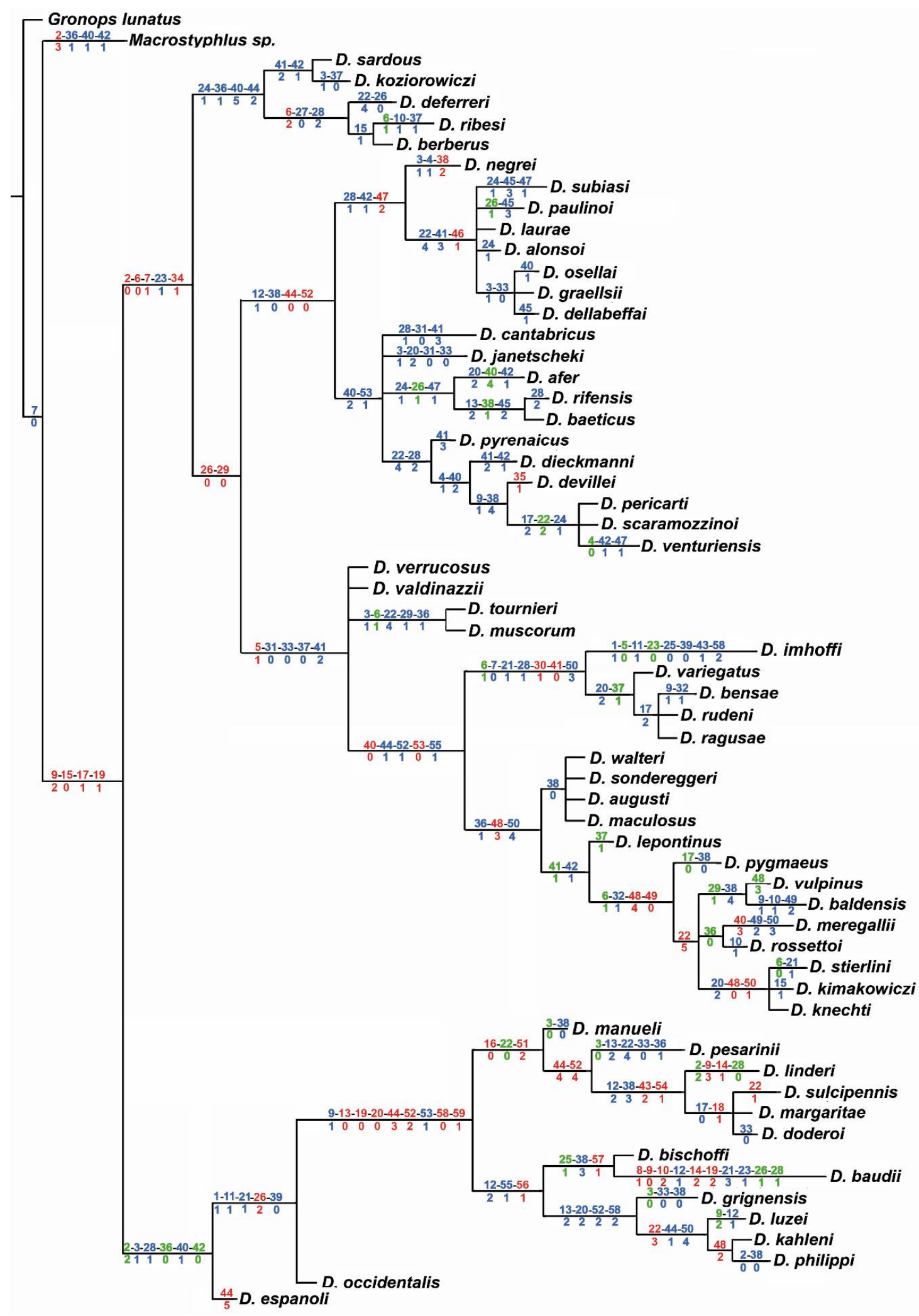

Figure 10. Synapomorphies and autapomorphies plotted on the MP consensus tree. Numbers above branches refer to the character, numbers below branches refer to the state of the character. Characters in red: synapomorphies and autapomorphies unique for the Dichotrachelus clade. Characters in blue: synapomorphies and autapomorphies not unique for the clade or the species. Characters in green: apparent reversals. 
Pronotum (Chars 17-22). Characters on the pronotum are quite variable, also intraspecifically. Depth and width of the median and dorso-lateral grooves, as well as curvature of the sides and ratio length/width, are more or less typical of each species, or occasionally of a species-complex, but show great polymorphism. Clade-specific states were observed in the ratio length/width and shape of the median groove in the D. sulcipennis complex (Char. 17.0; 18.1), depth of the median groove in many of the Saxifraga-associated species (Char. 19.0), width of the median groove in some species groups, such as the D. stierlini complex (Char. 20.2) and shape of the dorso-lateral grooves, shared by the species in the subgroup B3 (Char. 21.1).

Elytra. Like the pronotum, the width of elytra, their shape, elevation of the intervals, and other traits have strong intra- and interspecific variation, not always related to phylogenetic relationships. Some of the species have flat intervals on elytra, particularly in females (Char. 24.1; 26.1). The Saxifraga-associated species have typically highly convex odd intervals from the base to apex (Char. 26.2). One character of high interest is the shape of the striae, which are very narrow, with punctures merged to form a deep narrow furrow in many of the species of clade A (Char. 27.0), excluding those of the D. devillei group, that, like the species of clade $B$, have broad, visible punctures on the striae (Char. 27.1). The vestiture of scales and setae shows quite a high level of parallelism. However, the small-sized species of clade B, excluding the D. rudeni complex, have some setae also present on the even intervals (Char. 28.1), whereas these are usually missing in the other species of clade B (Char. 28.0). This character is variable in the species of clade A, but in the subgroup A2 the even intervals have no scales on the dorsum, and a few are present on declivity (Char. 28.2).

Legs. The legs are generally rather slender, with the exception of the species of subgroup B2, which have short and robust tibiae (Char. 32.1); their setae are usually relatively broad, except in the Saxifraga-associated species. The shape of segment 3 of the tarsi (Char. 38), narrow or with more or less broadened lobes, is typical of some species-groups, but the same state appears homoplastically in distinct lineages, and occasionally even closely related species have differences in the width of the lobes.

Genitalia. Male genitalia proved to be the most important character in inferring phylogenetic relationships in the genus. This was already evidenced for the Saxifraga-associated species, and is now confirmed for the entire genus, even though not all characters used bear the same phylogenetic signal. The penis is generally relatively short in the majority of the small-sized species (Char. 39.0), and more slender in the Saxifraga-associated taxa (Char. 39.1). The shape of its apex varies to a great extent (Char. 40), but the different states are usually shared between closely related species, as well as its dorsal sclerotization (Char. 41). The length of the internal sac (Char. 44) and the position of the genital sclerite, however, closely reflect taxonomic affinities. The most useful structure for inferring relationships among the species of the genus proved to be the male genital sclerite (Chars 45-57), as we have extensively discussed. Female genitalia, conversely, made only a limited contribution, and most of them were discarded after the first analyses, since they proved to be generally uniform and occasionally quite variable within the same species.

\section{Conclusions and Future Developments}

With the present study it was possible to infer the phylogenetic structure of the genus Dichotrachelus, supporting its isolated position in Palaearctic fauna and suggesting a very ancient diversification in Cyclominae. The present day species apparently derive from an ancestral split that led to two main lineages, one associated with the Iberian plate and the other with the alpine arch in a wide sense, with an apparently more recent penetration into the Apennines by a single lineage. The relationships of the species from the Sardinian and Corsican plate, and part of those from northern Africa and the Iberian plate (the D. ribesi and D. espanoli species-groups), are not fully understood. They might be old relicts of the first lineages that differentiated, but this cannot yet be determined with full confidence. Groups of closely related species are rather clearly defined, but thus far the more distant relationships could not be disclosed with sufficient precision. Our study confirms some of the 
biogeographical hypotheses that were previously proposed $[19,20]$, at least regarding the alpine taxa; however, more data are required to fully define the biogeographic scenario that led to the present day distribution of the separate lineages.

Future research will concentrate on achieving a broader set of molecular data from more species of the genus, also based on nuclear genes, and from a larger number of taxa of Cyclominae. This should hopefully allow the deep phylogeny of the genus to be inferred with more confidence, disclosing its true relationship in the subfamily, and reconstructing its evolution in the territories of the Peri-Tethys.

Supplementary Materials: The following are available online at http://www.mdpi.com/1424-2818/10/3/66/s1, Table I. List of the species and specimens examined. For the $m t$-Cox1 analysis, specimens sequenced in Turin are indicated with an asterisk; Table II Characters matrix for the morphological analysis; Table III. Pairwise distance of $m t$-Cox 1 , bases. The number of base differences per site from between sequences are shown. There were a total of 774 positions in the final dataset; Table IV. Pairwise distance of $m t$-Cox1, amino acids. The number of amino acid substitutions per site from between sequences is shown. Analyses were conducted using the Poisson correction model. The rate variation among sites was modelled with a gamma distribution (shape parameter $=1$ ). The coding data was translated assuming a Invertebrate Mitochondrial genetic code table. There were a total of 258 positions in the final dataset.

Author Contributions: All authors contributed equally to the design, analysis and writing of the paper.

Funding: The research had the financial support by the Swiss Federal Office for the Environment (BAFU/FOEN) and the Turin University Research Fund ex-60\% (2016-2017).

Acknowledgments: C.G. and M.B. are thankful to Sofia Wyler and Jan Pawlowski (University of Geneva, Switzerland) for their steady support during the SwissBOL project where part of the molecular data used here could be gained, with financial support by the Swiss Federal Office for the Environment (BAFU/FOEN). We are thankful to Manfred Kahlen (Innsbruck, Austria), Alexander Szallies (ZHAW Life Sciences und Facility Management, Switzerland), Jiří Krátký (Hradec Králové, Czech Republic), and Jiří Brestovanský (Neratovice, Czech Republic) for the possibility to use their samples. J.J. Morrone (UNAM, Mexico) has kindly confirmed the identification of the specimens of Macrostyphlus. Max Barclay (Natural History Museum, London) kindly checked the English.

Conflicts of Interest: The authors declare no conflict of interest.

\section{References}

1. Alonso-Zarazaga, M.A.; Barrios, H.; Borovec, R.; Bouchard, P.; Caldara, R.; Colonnelli, E.; Gültekin, L.; Hlaváč, P.; Korotyaev, B.; Lyal, C.H.C.; et al. Cooperative Catalogue of Palaearctic Coleoptera Curculionoidea. Monografías Electrónicas SEA 2017, 8, 1-729.

2. Oberprieler, R.G. A reclassification of the weevil subfamily Cyclominae (Coleoptera: Curculionidae). Zootaxa 2010, 2515, 1-35.

3. Stierlin, G. Revision der Dichotrachelus-Arten. Mitteilungen der Schweizerischen Entomologischen Gesellschaft 1878, 5, 392-425.

4. Stierlin, G. Fauna Coleopterorum Helvetica. Teil II; Bolli und Boecherer: Schaffhausen, Switzerland, 1898 ; p. 662.

5. Franz, H. Die südwesteuropäischen Arten der Gattung Dichotrachelus (Col. Curc.). Koleopterol. Rundsch. 1954, 23, 93-96.

6. González, M. Los Dichotrachelus ibéricos (Col. Curculionidae). Publicaciones del Instituto de Biología Aplicada 1964, 37, 5-16.

7. Meregalli, M. Revisione delle specie iberiche del genere Dichotrachelus Stierlin, 1853 (Coleoptera, Curculionidae). MRSN 1987, 5, 335-418.

8. Hustache, A. Curculionides gallo-rhénans (suite). Ann. Soc. Entomol. Fr. 1929, 98, 1-96.

9. Hoffmann, A. Coléoptères Curculionides. Deuxième Partie. Faune Fr. 1954, 59, 488-1208.

10. Barajon, M. Le specie Italiane del Gen. Dichotrachelus Stierl. (Col. Curculionidae). Estratto dalle Memorie del Museo Civico di Storia Naturale 1946, 85, 112-129.

11. Barajon, M. Le specie Italiane del Gen. Dichotrachelus Stierl. II. Estratto dalle Memorie del Museo Civico di Storia Naturale Milano 1947, 86, 31-32.

12. Osella, G. Revisione delle specie Italiane del Genere Dichotrachelus Stierlin (Coleoptera, Curculionidae). Estratto dalle Memorie del Museo Civico di Storia Naturale 1967, 15, 349-445. 
13. Osella, G. Revisione del genere Dichotrachelus Stierlin. Estratto dalle Memorie del Museo Civico di Storia Naturale 1970, 18, 449-569.

14. Germann, C. About the enigmatic Dichotrachelus valesiacus Stierlin, 1878 (Coleoptera, Curculionidae, Cyclominae). Zookeys 2009, 5, 81-86. [CrossRef]

15. Germann, C. Review of the Dichotrachelus alpestris Stierlin, 1878 species group with evidence for a species complex of D. augusti F. Solari, 1946, and D. sondereggeri sp. nov. from Switzerland (Coleoptera, Curculionidae). Contrib. Nat. Hist. 2011, 17, 1-21.

16. Germann, C.; Baur, H. Notes on the taxonomy and biology of Dichotrachelus imhoffi Stierlin, 1857 (Coleoptera, Curculionidae) with the observation of a length dimorphism of the aedeagus. Mitteilungen der Schweizerischen Entomologischen Gesellschaft 2010, 83, 249-260.

17. Germann, C. Die Rüsselkäfer der Schweiz-Checkliste (Coleoptera, Curculionoidea) mit Verbreitungsangaben nach biogeografischen Regionen. Mitteilungen der Schweizerischen Entomologischen Gesellschaft 2010, 83, 41-118.

18. Germann, C. Supplement zur Checkliste der Rüsselkäfer der Schweiz (Coleoptera, Curculionoidea). Mitteilungen der Schweizerischen Entomologischen Gesellschaft 2011, 84, 155-169.

19. Meregalli, M.; Menardo, F.; Klass, K.-D.; Cervella, P. Phylogeny of the Saxifraga-associated species of Dichotrachelus (Insecta: Coleoptera: Curculionidae), with remarks on their radiation in the Alps. Arthropod Syst. Phylogeny 2013, 71, 43-68.

20. Meregalli, M.; Monguzzi, R.; Klass, K.-D.; Cervella, P.; Kahlen, M. Dichotrachelus pesarinii sp.n., a missing link between the species from the central and the western southern Alps (Coleoptera: Curculionidae: Cyclominae). Arthropod Syst. Phylogeny 2015, 73, 323-332.

21. Germann, C.; Wyler, S.; Bernasconi, M. DNA barcoding of selected alpine beetles with focus on Curculionoidea (Coleoptera). Rev. Suisse Zool. 2017, 124, 15-38.

22. Morrone, J.J. Annotated checklist of the tribe Listroderini (Coleoptera: Curculionidae: Cyclominae). Zootaxa 2011, 3119, 1-68.

23. Marvaldi, A.E.; Sequeira, A.S.; O’Brien, C.W.; Farrell, B.D. Molecular and morphological phylogenetics of weevils (Coleoptera, Curculionoidea): Do niche shifts accompany diversification? Syst. Biol. 2002, 51, 761-785. [CrossRef] [PubMed]

24. Riedel, A.; Daawia, D.; Blake, M. Deep COX1 divergence and hyperdiversity of Trigonopterus weevils in a new Guinea mountain range (Coleoptera Curculionidae). Zool. Scr. 2009, 39, 63-74. [CrossRef]

25. Hughes, J.; Vogler, A.P. The phylogeny of acorn weevils (genus Curculio) from mitochondrial and nuclear DNA sequences: The problem of incomplete data. Mol. Phylogenet. Evol. 2004, 32, 601-615. [CrossRef] [PubMed]

26. Ronquist, F.; Teslenko, M.; Van der Mark, P.; Ayres, D.L.; Darling, A.; Höhna, S.; Larget, B.; Liu, L.; Suchard, M.A.; Huelsenbeck, J.P. MrBayes 3.2: Efficient bayesian phylogenetic inference and model choice across a large model space. Syst. Biol. 2012, 61, 539-542. [CrossRef] [PubMed]

27. Ronquist, F.; Van der Mark, P.; Huelsenbeck, J.P. Bayesian phylogenetic analysis using MrBayes. In The Phylogenetic Handbook: A Practical Approach to Phylogenetic Analysis and Hypothesis Testing; Lemey, P., Salemi, M., Vandamme, A.M., Eds.; Cambridge University Press: Cambridge, UK, 2009; p. 723.

28. Goloboff, P.A.; Farris, J.S.; Nixon, K.C. TNT, a free program for phylogenetic analysis. Cladistics 2008, 24, 774-786. [CrossRef]

29. Silvestro, D.; Michalak, I. RAxML GUI: A graphical front-end for RAxML. Org. Divers. Evol. 2011, 12, 335-337. [CrossRef]

30. Goldman, N.; Yang, Z. A codon-based model of nucleotide substitution for protein-coding DNA sequences. Mol. Biol. Evol. 1994, 11, 725-736. [PubMed]

31. Baele, G.; Lemey, P. Bayesian evolutionary model testing in the phylogenomics era: Matching model complexity with computational efficiency. Bioinformatics 2013, 29, 1970-1979. [CrossRef] [PubMed]

32. Huelsenbeck, J.P.; Larget, B.; Alfaro, M.E. Bayesian phylogenetic model selection using reversible jump Markov chain Monte Carlo. Mol. Biol. Evol. 2004, 21, 1123-1133. [CrossRef] [PubMed]

33. Wright, A.M.; Hillis, D.M. Bayesian Analysis Using a Simple Likelihood Model Outperforms Parsimony for Estimation of Phylogeny from Discrete Morphological Data. PLoS ONE 2014, 9, e109210. [CrossRef] [PubMed] 
34. Gillett, C.P.D.T.; Lyal, C.H.C.; Vogler, A.P.; Emerson, B.C. Statistical Evaluation of Monophyly in the 'Broad-Nosed Weevils' through Molecular Phylogenetic Analysis Combining Mitochondrial Genome and Single-Locus Sequences (Curculionidae: Entiminae, Cyclominae, and Hyperinae). Diversity 2018, 10, 21. [CrossRef]

35. Alonso-Zarazaga, M.A.; Lyal, C.H.C. A World Catalogue of Families and Genera of Curculionoidea (Insecta: Coleoptera). (Excepting Scolytidae and Platypodidae); Entomopraxis, S.C.P., Ed.; Entomopraxis: Barcelona, Spain, $1999 ;$ p. 315.

36. Bik, H.M.; Lambshead, P.J.; Thomas, W.K.; Lunt, D.H. Moving towards a complete molecular framework of the Nematoda: A focus on the Enoplida and early-branching clades. BMC Evol. Biol. 2010, 10, 353. [CrossRef] [PubMed]

37. Song, N.; Li, H.; Song, F.; Cai, W. Molecular phylogeny of Polyneoptera (Insecta) inferred from expanded mitogenomic data. Sci. Rep. 2016, 6, 36175. [CrossRef] [PubMed]

38. Wang, M.; Lv, S. Substitution saturation analysis of mitochondrial cytochrome C oxidase subunit 1 (Cox1) gene of Angiostrongylus cantonensis. Chin. J. Parasitol. Parasit. Dis. 2014, 32, 205-209.

39. Stüben, P.E.; André Schütte, A.; Bayer, C.; Astrin, J.J. The Molecular Weevil Identification Project (Coleoptera: Curculionoidea), Part II-Towards an Integrative Taxonomy. Snudebiller 2015, 16, 1-316.

40. Gillett, C.P.D.T.; Crampton-Platt, A.; Timmermans, M.J.T.N.; Jordal, B.H.; Emerson, B.C.; Vogler, A.P. Bulk de novo mitogenome assembly from pooled total DNA elucidates the phylogeny of Weevils (Coleoptera: Curculionoidea). Mol. Biol. Evol. 2014, 31, 2223-2237. [CrossRef] [PubMed]

41. Morrone, J.J. Cladistics of the New World genera of Listroderina (Coleoptera: Curculionidae: Rhytirrhinini). Cladistics 1997, 13, 247-266. [CrossRef]

42. Morrone, J.J. The subtribes and genera of the tribe Listroderini (Coleoptera, Curculionidae, Cyclominae): Phylogenetic analysis with systematic and biogeographical accounts. Zookeys 2013, 273, 15-71. [CrossRef] [PubMed]

43. Kuschel, G. Insects of Campbell Island Coleoptera: Curculionidae of the Subantarctic islands of New Zealand. Pac. Insects Monogr. 1964, 1, 416-493.

44. Kuschel, G. Entomology of the Aucklands and other islands south of New Zealand: Coleoptera: Curculionidae. Pac. Insects Monogr. 1971, 27, 225-259.

45. Chown, S.L.; Scholtz, C.H. Cryptogam herbivory in Curculionidae from the sub-Antarctic Prince Edward Islands. Coleopt. Bull. 1989, 43, 165-169.

46. McKenna, D.D.; Sequeira, A.S.; Marvaldi, A.E.; Farrell, B.D. Temporal lags and overlap in the diversification of weevils and flowering plants. Proc. Natl. Acad. Sci. USA 2009, 106, 7083-7088. [CrossRef] [PubMed]

47. Frisch, W.; Meschede, M. Plattentektonik 2; Wissenschaftliche Buchgesellschaft: Darmstadt, Germany, $2007 ;$ p. 196.

48. Péricart, J. Notes sur divers Curculionidae français avec la description d'une espèce et d'une sous-espèce nouvelles (Coleoptera). Nouv. Rev. Entomol. 1974, 4, 55-70.

49. Meregalli, M. Osservazioni preliminari sulla biologia dei Dichotrachelus (Coleoptera, Curculionidae). In Proceedings of the XII Congresso Nazionale Italiano di Entomologia, Roma, Italy, 5-9 November 1980; pp. 125-133.

(C) 2018 by the authors. Licensee MDPI, Basel, Switzerland. This article is an open access article distributed under the terms and conditions of the Creative Commons Attribution (CC BY) license (http:/ / creativecommons.org/licenses/by/4.0/). 